\title{
Numerical simulation investigations of coalbed methane drainage performance with multilateral well
}

\author{
Songze Liu ${ }^{1}$ Jianguang Wei ${ }^{1,2} \cdot$ Yuanyuan Ma ${ }^{1}$ D $\cdot$ Hongliang Liu ${ }^{3} \cdot$ Xuemei Liu ${ }^{4} \cdot$ Bingxu Yan $^{5}$
}

Received: 30 October 2020 / Accepted: 1 February 2021 / Published online: 7 March 2021

(c) The Author(s) 2021

\begin{abstract}
A novel multilateral well for coalbed methane extraction was proposed in the study. There is a main wellbore at the longitudinal center of coal seam and four lateral wells at the horizontal center in the multilateral-well system. Compared with traditional drainage holes, multilateral-well system has a better performance on coalbed methane development. A hydraulic-mechanical coupling model of multilateral well was established, the pressure and permeability ratio distribution of the gas extraction process were analyzed comprehensively. The sensitivity analysis of lateral number, length distribution and intersection angle of multilateral-well system were studied. The results indicate that there is a minimum gas pressure distribution around the multilateral well and the overall permeability of coal seams increases with production time and the permeability around the multilateral well is larger than the area away from the multilateral well which induced by the gas desorb and matrix shrink. The quantity of lateral wells has a positive effect on cumulative production. When the total length of lateral wells is equal, the uniformity and symmetry of lateral length distribution are two key factors on the gas extraction performance. The minimum intersection angle has a positive effect on cumulative production. This study provides a better alternative for traditional drainage hole to obtain greater coalbed methane performance.
\end{abstract}

Keywords Numerical simulation $\cdot$ Multilateral well $\cdot$ Hydraulic-Mechanical coupling $\cdot$ Sensitivity analysis $\cdot$ Gas extraction performance

Jianguang Wei

3106097170@qq.com

$\triangle$ Yuanyuan Ma mayuanyuan_1991@outlook.com

1 Department of Petroleum Engineering, Northeast Petroleum University, Heilongjiang Province, Daqing 163318, China

2 Key Laboratory of Continental Shale Hydrocarbon Accumulation and Efficient Development (Northeast Petroleum University), Ministry of Education, Daqing 163318, China

3 PetroChina Changqing Oilfield No. 1 Oil Production Plant, Yanan 716000, China

4 PetroChina Daqing Oilfield No. 1 Oil Production Plant, Daqing 163318, China

5 PetroChina Tarim Oilfield Dina Oil and Gas Development Department, Kuerle 841000, China

\section{Introduction}

The development and utilization of clean resources has long been a question of great interest worldwide (Uddin et al. 2015; Prabu and Mallick 2015; Luo et al. 2011; Chen et al. 2019a; Ma et al. 2020a, 2020b). As an important component of clean resources, coalbed methane (CBM) has become an important part of energy supply (Fan et al. 2019; Wang et al. 2018; Fan and Liu 2018; Feng et al. 2018; Yu and Wang 2020; Talapatra 2020). China's CBM resources within a buried depth of $2000 \mathrm{~m}$ can reach $36.8 \times 10^{12} \mathrm{~m}^{3}$ and China has over 40 years' experience in CBM development (Mu et al. 2015; Luo et al. 2019; Xu et al. 2019). China has drilled about 20,000 CBM wells by 2015 , but only a quarter of them were capable of mining gas commercially (Yan et al. 2019; $\mathrm{Li}$ et al. 2015). Achieving high efficiency and high yield of CBM wells has always been a key issue for scholars at home and abroad (Li et al. 2019; Wei et al. 2019a; Sun et al. 2019; Qin et al. 2018; Mohammed et al. 2020; Xiong et al. 2020; Talapatra and Karim 2020). 
The well is the key issue for the highly efficient development of CBM reservoirs (Wei et al. 2019b; Yang et al. 2017; Chen et al. 2019b; Moore et al. 2015). Zhang (Zhang et al. 2018) conducted gas drainage experiments to optimize the borehole length; the results shows that longer boreholes resulted in higher gas production and the relationship between gas production and bore hole length is a logarithmic function. Liu (Liu et al. 2013) optimized the drainage parameters of CBM wells in southern Qinshui Basin of China and the results indicated that the maximum wellhead pressure should be maintained around $1.5 \mathrm{MPa}$ before stable production, and between $0.10 \mathrm{MPa}$ and $0.30 \mathrm{MPa}$ after stable production. Liu (Liu et al. 2018) also analyzed the inter-well interference during multi-well drainage in CBM production areas and found that the inter-well interference during multiwell drainage increases and then begins to stabilize, established geochemical response model and evaluation program of inter-well interference. Shi (Shi et al. 2019) established the pressure propagation model for vertically fractured CBM wells and vertical CBM wells without fracturing under the condition of considering variable mass flow within hydraulic fracture and hydraulic fracture conductivity decrease; the results showed that the cumulative gas production of CBM wells (CGPC) decreases sharply when permeability is less than $0.5 \mathrm{mD}$. Yang (Yang et al. 2018) developed a semi-analytical model to predict gas and water production in CBM reservoirs with multiscale fracture networks and the model was applied to quantify the effects of fracture network complexity, connectivity and stress sensitivity on extraction performance. An (An et al. 2015) compared the CBM mining performance of horizontal producer parallel to butt cleats and the alternative well configuration where the orientation of horizontal producers is parallel to face cleats; the results indicated that the former well configuration the producers can intersect the maximum number of
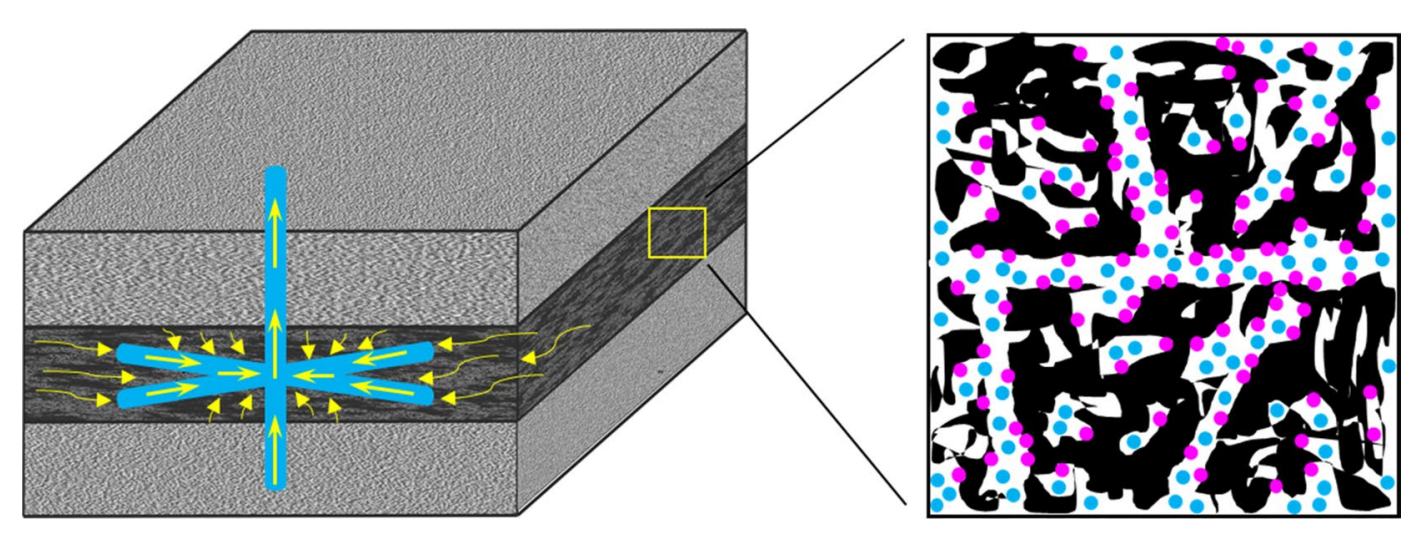

Fig. 1 Schematic of multilateral well in coal seams

high-permeability pathways. Vishal (Vishal et al. 2013) designed one $\mathrm{CO}_{2}$ injector well and two methane producer wells for CBM development and found that the methane production is significantly enhanced due to injection of $\mathrm{CO}_{2}$.

Previous studies mainly focused on the vertical wells, horizontal wells and drainage holes in CBM reservoir, there is a deficiency investigation on the application of multilateral wells in CBM reservoir. Therefore, this study proposed a novel multilateral well for coalbed methane development. In the multilateral-well system, there is a main wellbore at the longitudinal center of coal seam and four lateral wells at the horizontal center as shown in Fig. 1. A hydraulic-mechanical coupling model was established for the novel multilateralwell system. Based on the model, the pressure distribution and permeability distribution of the gas extraction process with multilateral well were analyzed comprehensively. The gas extraction performance with multilateral well and drainage holes were compared; the sensitivity analysis of lateral number, length distribution and intersection angle of multilateral well system were studied.

\section{Model description}

\section{Model assumptions}

This study set out to investigate the gas extraction performance in coal seam with multilateral well. In order to analyze the process of coalbed methane extraction clearly, some unimportant factors have been eliminated. The following major assumptions are made to establish the numerical model (Liu et al. 2017a, 2017b, 2017c): (1) the coal seam is regarded as an idealized porous media with properties of homogeneous and isotropic; (2) the gas migration is singlephase flow and the process can be described by Darcy's Law; (3) the gas desorption process conforms to the Langmuir equation; (4) The temperature of coal seam is assumed to be constant and neglects the effect of temperature on gas 
desorption; (5) No flow boundary condition is set around the coal seam, the coal is saturated with gas and ignores the effect of water on gas migration; (6) the gas volume force is not considered.

\section{Governing equation}

\section{Seepage governing equation}

The mass conservation equation of gas migration in coal seams can be expressed as follows

$\nabla\left(\rho_{\mathrm{g}} u_{\mathrm{g}}\right)+\frac{\partial C}{\partial t}=0$

where $\rho_{\mathrm{g}}\left(\mathrm{kg} / \mathrm{m}^{3}\right)$ is the gas density, $u_{\mathrm{g}}(\mathrm{m} / \mathrm{s})$ is the gas seepage velocity, $C\left(\mathrm{~kg} / \mathrm{m}^{3}\right)$ is the gas content in coal seams and $t$ (s) denotes the time. The gas seepage velocity $u_{\mathrm{g}}$ can be described by Darcy's Law

$u_{\mathrm{g}}=-\frac{k}{\mu} \nabla p_{g}$,

where $p_{\mathrm{g}}(\mathrm{Pa})$ is the gas pressure, $\mathrm{k}\left(\mathrm{m}^{2}\right)$ is the effective permeability of the coal seams and $\mu(\mathrm{Pa} \cdot \mathrm{s})$ is the gas dynamic viscosity. The gas content $C$ in coal seams is written as follows

$C=C_{\mathrm{a}}+C_{\mathrm{f}}$

$C_{\mathrm{a}}=\frac{p_{\mathrm{g}} a b}{1+b p_{\mathrm{g}}} \rho_{\mathrm{c}} \rho_{\mathrm{g}}$

$C_{\mathrm{f}}=\varphi \rho_{\mathrm{g}}$,

where $C_{a}\left(\mathrm{~kg} / \mathrm{m}^{3}\right)$ and $C_{f}\left(\mathrm{~kg} / \mathrm{m}^{3}\right)$ represent adsorption gas content and free gas content, $\varphi$ and $\rho_{c}\left(\mathrm{~kg} / \mathrm{m}^{3}\right)$ represent the porosity and density of coal seams, $a$ and $b$ represent Langmuir adsorption constant and pressure constant, respectively. The parameter $\rho_{g}$ can be calculated by the modified ideal gas state equation as follows

$\rho_{\mathrm{g}}=\frac{M}{R T} \frac{p_{\mathrm{g}}}{Z}$

where $M(\mathrm{~kg} / \mathrm{mol})$ is the gas molar mass, $R(8.314 \mathrm{~J} /(\mathrm{K} \cdot \mathrm{mol}))$ is the ideal gas constant, $T(K)$ is the ambient temperature and $Z$ is the gas compression factor. Substituting Eqs. (2), (3) and (6) into Eq. (1), the gas seepage governing equation in coal seams is obtained:

$\nabla\left(-\frac{M}{R T} \frac{p_{\mathrm{g}}}{Z} \cdot \frac{k}{\mu} \nabla p_{\mathrm{g}}\right)+\frac{\partial}{\partial t}\left(\frac{p_{\mathrm{g}} a b}{1+b p_{\mathrm{g}}} \rho_{\mathrm{c}} \cdot \frac{M}{R T} \frac{p_{\mathrm{g}}}{Z}+\varphi \cdot \frac{M}{R T} \frac{p_{\mathrm{g}}}{Z}\right)=0$
It can be observed from Eq. (7) that porosity and permeability of coal seams are the key parameters in the gas extraction process, and the porosity is defined as ( $\mathrm{Li}$ et al. 2016; Cui and Bustin 2005; Xia et al. 2015)

$\varphi=\alpha-\left(\alpha-\varphi_{0}\right) \exp \left(S_{0}-S\right)$

where $\varphi_{0}$ is the initial porosity, $\alpha$ is the Biot coefficient and $\alpha=1-\left(K / K_{\mathrm{s}}\right), K(\mathrm{GPa})$ is the bulk modulus of coal and $K=E / 3(1-2 v), K_{\mathrm{s}}(\mathrm{GPa})$ is the bulk modulus of coal skeleton and $K_{s}=E_{s} / 3(1-2 v), \varepsilon_{v}$ is the volume strain of coal, $S$ is the pore strain of coal and $S=\varepsilon_{\mathrm{v}}+p_{\mathrm{g}} / K-\varepsilon_{\mathrm{a}}, S_{0}$ is the initial pore strain of coal and $S_{0}=\varepsilon_{\mathrm{v} 0}+p_{\mathrm{g} 0} / K-\varepsilon_{\mathrm{a} 0}$. The subscript ' 0 ' represents the initial value of the corresponding variable. The relationship between permeability and porosity of coal seams can be described by the cubic law as follows

$\frac{k}{k_{0}}=\left(\frac{\varphi}{\varphi_{0}}\right)^{3}$,

where $k_{0}\left(\mathrm{~m}^{2}\right)$ represents the initial permeability of coal seams. Substituting Eq. (8) into Eq. (9), the detailed permeability equation is obtained

$k=k_{0}\left[\frac{\alpha}{\varphi_{0}}-\left(\frac{\alpha}{\varphi_{0}}-1\right) \exp \left(S_{0}-S\right)\right]^{3}$

\section{Mechanical governing field}

Based on the assumption, the total strain of coal is the result of stress, gas pressure and gas desorption, the relationship between stress and strain of coal can be expressed by (Wu et al. 2010)

$\varepsilon_{i j}=\frac{1}{2 G} \sigma_{i j}-\left(\frac{1}{6 G}-\frac{1}{9 K}\right) \sigma_{k k} \delta_{i j}+\frac{\alpha p_{g}}{3 K} \delta_{i j}+\frac{\varepsilon_{a}}{3} \delta_{i j}$,

where $\mathrm{G}(\mathrm{GPa})$ represents the shear modulus of coal and $G=E / 2(1+v), \mathrm{E}(\mathrm{GPa})$ and $\mathrm{E}_{\mathrm{s}}(\mathrm{GPa})$ denotes the elastic modulus of coal and coal skeleton, $v$ denotes the Poisson's ratio, $\delta_{i j}$ denotes the Kronecker factor and $\varepsilon_{a}$ denotes strain induced by skeleton gas adsorption. Furthermore, the geometric equation of coal deformation satisfies the Cauchy equation as follows

$\varepsilon_{i j}=\frac{u_{i, j}+u_{j, i}}{2}$,

where $u_{i, j}$ is the partial derivative in the $j$ direction of the displacement in the $i$ direction, $u_{j, i}$ is the partial derivative in the $i$ direction of the displacement in the $j$ direction. According to the elastic mechanics equation, the static equilibrium relationship of coal is expressed as

$\sigma_{i j, j}+F_{i}=0$, 
where $F_{i}(\mathrm{MPa})$ is the volume force. Combining Eqs. (11), (12) and (13), the mechanical field governing equation of coal-gas coupling is obtained

$G u_{i, j j}+\frac{G}{1-2 v} u_{j, j i}-\alpha p_{g, i}-K \varepsilon_{s, i}+F_{i}=0$

The cross-coupling and the HM governing equations of gas extraction is illustrated in Fig. 2.

\section{A multilateral-well case}

\section{Computational model}

Based on the mathematical coupling model of coal deformation and gas flow proposed in this paper, an idealized of gas extraction model with multilateral wells is established, as shown in Fig. 3. The computational domain is a $400 \mathrm{~m} \times 400 \mathrm{~m} \times 5 \mathrm{~m}$ hexahedral located at a depth of $800-805 \mathrm{~m}$. There is a main wellbore with a radius of $0.15 \mathrm{~m}$ at the longitudinal center of coal seam and 4 lateral wells with a radius of $0.10 \mathrm{~m}$ at the horizontal center of coal seam. The length of lateral wells is $100 \mathrm{~m}$, and the angle between two adjacent lateral well is $90^{\circ}$.

\section{Initial and boundary conditions}

The initial gas pressure of coal seams and the extraction pressure of boreholes are set as $0.7 \mathrm{MPa}$ and $0.076 \mathrm{MPa}$, respectively. The upper boundary pressure of coal seams is equal to the overburden pressure of $20 \mathrm{MPa}$, and the bottom boundary is fixed. The surrounding boundary is bounded by the normal displacement and all external boundaries are insulted. The other major parameters are listed in Table. 1.
Fig. 2 Cross-coupling and the HM governing equations of gas extraction

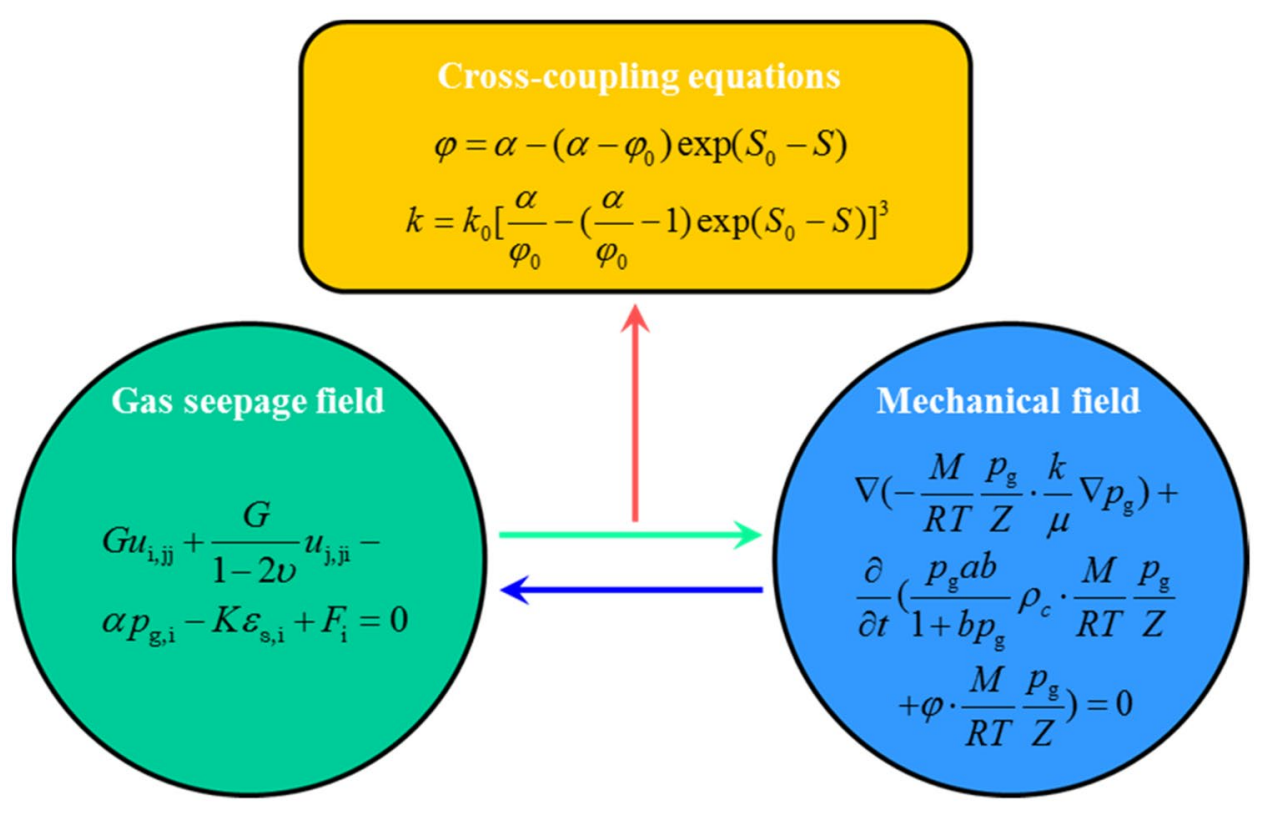

Fig. 3 Schematic of the computational model
3D diagram

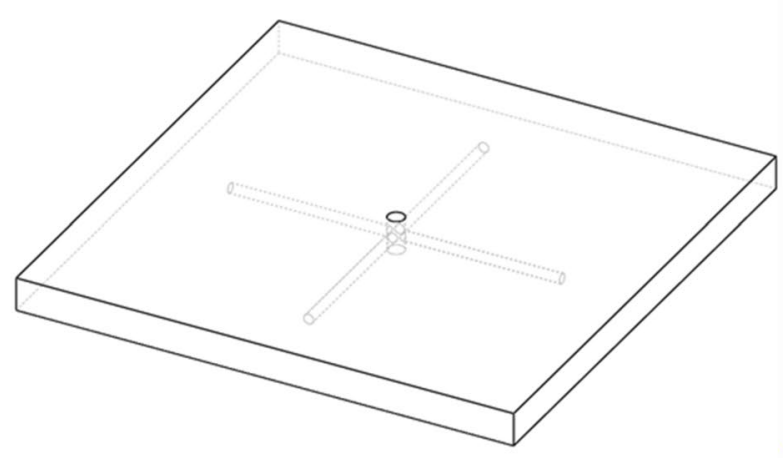

Elevation profile

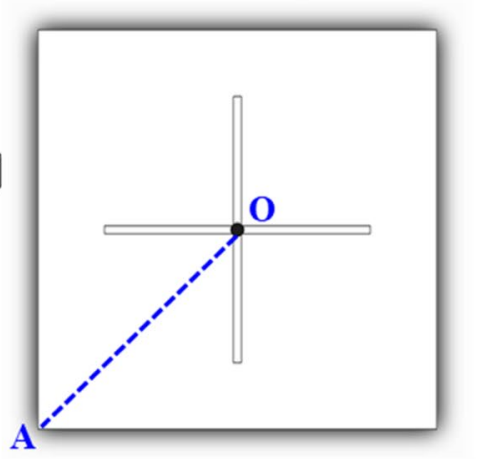


Table 1 Model basic parameters

\begin{tabular}{ll}
\hline Description & Value \\
\hline Initial gas pressure of coal seam, MPa & 0.7 \\
Extraction pressure of boreholes, MPa & 0.076 \\
Initial permeability of coal seam, ${ }^{2}$ & $2.0 \times 10^{-15}$ \\
Elastic modulus of coal, GPa & 2.713 \\
Elastic modulus of coal skeleton, GPa & 8.469 \\
Poisson's ratio of coal, / & 0.32 \\
Initial porosity of coal, / & 0.04 \\
Dynamic viscosity of gas, Pa·s & $1.03 \times 10^{-5}$ \\
Density of coal seams, $\mathrm{kg} / \mathrm{m}^{3}$ & 1380 \\
Density at standard conditions of gas, $\mathrm{kg} / \mathrm{m}^{3}$ & 0.717 \\
Langmuir adsorption constant, $\mathrm{m}^{3} / \mathrm{kg}$ & 0.03832 \\
Langmuir pressure constant, $1 / \mathrm{Pa}$ & $5.11 \times 10^{-7}$ \\
Adsorption strain coefficient, $\mathrm{kg} / \mathrm{m}^{3}$ & 0.06 \\
Temperature of coal seams, $\mathrm{K}$ & 298.5 \\
\hline
\end{tabular}

\section{Description of well arrangements}

Figure 4 illustrates sectional views of 12 different well arrangements. In Fig. 4, the while circular planes represent the main wellbore, the blue lines represent lateral wells, the red lines represent the drainage hole and the gray region represent coal seams.

For Case 2, Base Case and Case 5, the number of lateral wells is 2, 4, 6 and the total length of lateral wells is $200 \mathrm{~m}$, $400 \mathrm{~m}$ and $600 \mathrm{~m}$, respectively. For Case 1, Case 3 and Case 5, the number of drainage holes is 1, 2, 3 and the total length of drainage holes is $200 \mathrm{~m}, 400 \mathrm{~m}, 600 \mathrm{~m}$, respectively. These six Cases are designed to compare the effect of gas extraction performance of coal seams with multilateral well and drainage holes.

For Case 6, the length of lateral wells is $95 \mathrm{~m}, 105 \mathrm{~m}$, $95 \mathrm{~m}$ and $105 \mathrm{~m}$ from (1) to (4), respectively. For Case 7, the length of lateral wells is $90 \mathrm{~m}, 110 \mathrm{~m}, 90 \mathrm{~m}$ and $110 \mathrm{~m}$ from (1) to (4), respectively. For Case 8, the length of lateral wells is $95 \mathrm{~m}, 95 \mathrm{~m}, 105 \mathrm{~m}$ and $105 \mathrm{~m}$ from (1) to (4), respectively. For Case 9, the length of lateral wells is $90 \mathrm{~m}, 90 \mathrm{~m}, 110 \mathrm{~m}$ and

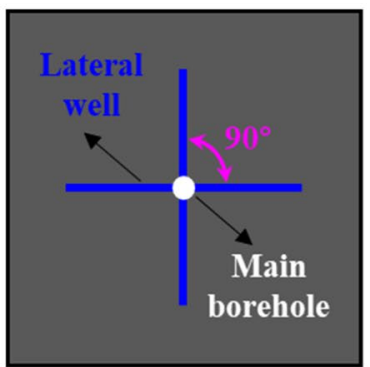

Base Case

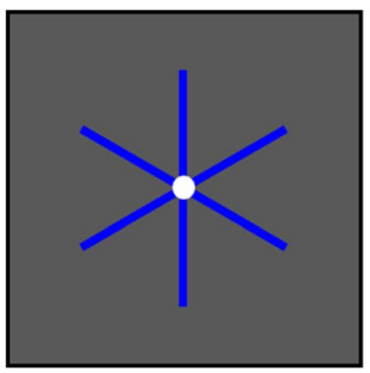

Case 4

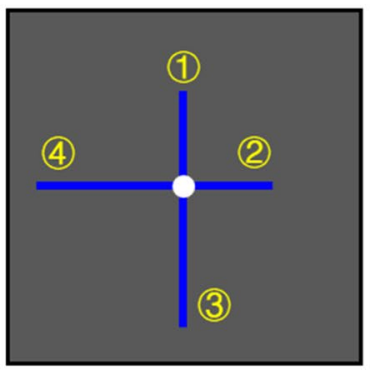

Case 8

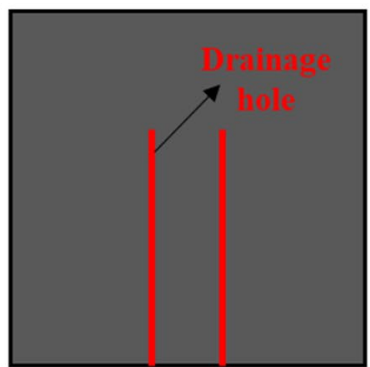

Case 1

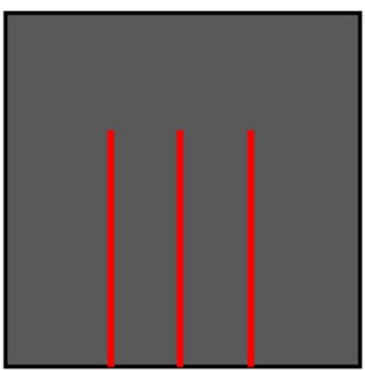

Case 5

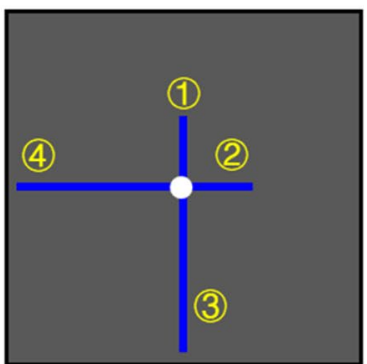

Case 9

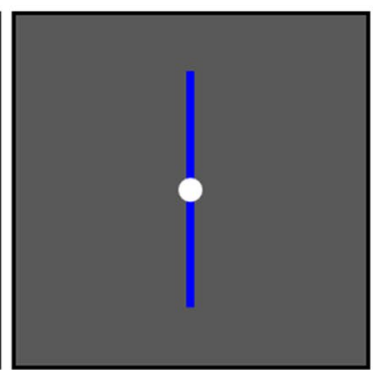

Case 2

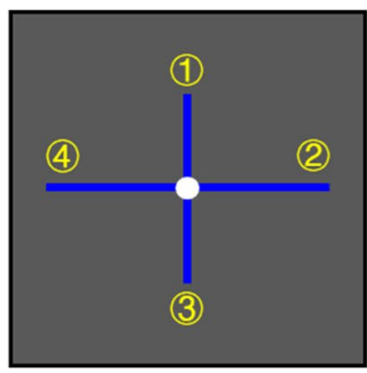

Case 6

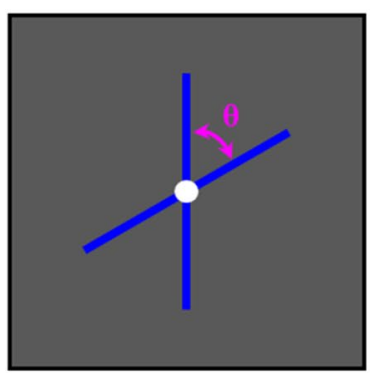

Case 10-Case 13

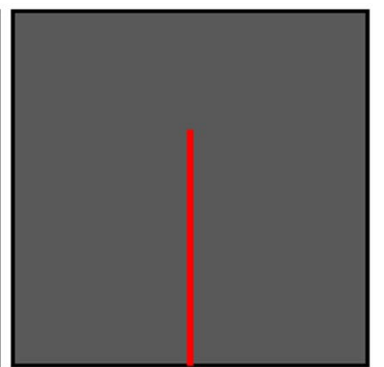

Case 3

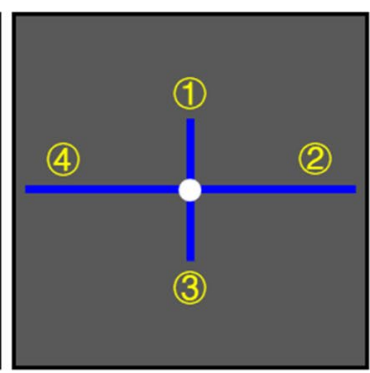

Case 7

Case 10: $\theta=80^{\circ}$

Case 11: $\theta=70^{\circ}$

Case 12: $\theta=60^{\circ}$

Case 13: $\theta=50^{\circ}$

Fig. 4 Sectional views of 13 different well arrangements 
$110 \mathrm{~m}$ from (1) to (4), respectively. The total length of lateral wells is equal of $400 \mathrm{~m}$ for Base Case and Case 6-9, these 5 Cases are designed to investigate the effect of lateral length distribution on gas extraction performance.

For Base Case, the angle between two adjacent lateral wells is $90^{\circ}$. In order to study the effect of angle between lateral well on gas extraction performance, Case 10-Case 13 are designed. From Case 10 to Case 13, the minimum angle between two adjacent lateral wells is $80^{\circ}, 70^{\circ}, 60^{\circ}$ and $50^{\circ}$, respectively.

\section{Results and discussion}

\section{Analysis of pressure and permeability rate variation}

In order to study the gas extraction process in coal seams, variation of pressure distribution and permeability rate distribution was analyzed. The pressure contours and permeability ratio under different times of $10 \mathrm{~d}, 50 \mathrm{~d}, 100 \mathrm{~d}, 200 \mathrm{~d}$, $600 \mathrm{~d}, 1200 \mathrm{~d}, 2000 \mathrm{~d}$ and $3000 \mathrm{~d}$ were investigated as shown in Figs. 5 and 6, respectively. As Fig. 5 demonstrates that the pore pressure decreases and its variation rate decreases

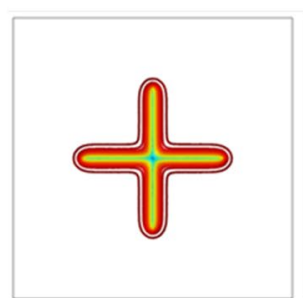

(a) $10 \mathrm{~d}$

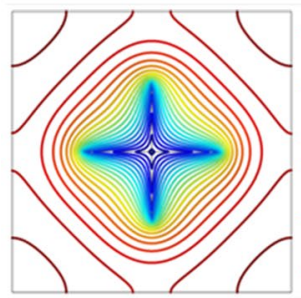

(e) $600 \mathrm{~d}$

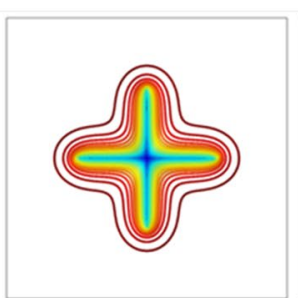

(b) $50 \mathrm{~d}$

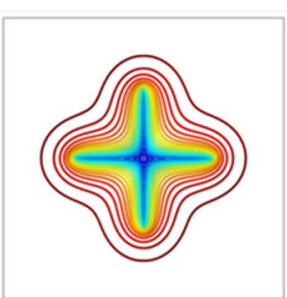

(c) $100 \mathrm{~d}$

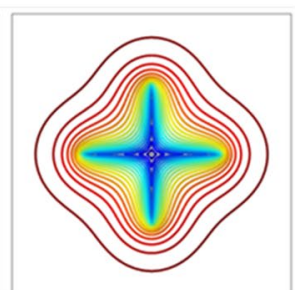

(d) $200 \mathrm{~d}$

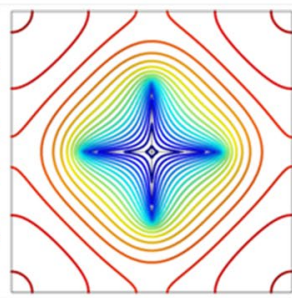

(f) $1200 \mathrm{~d}$

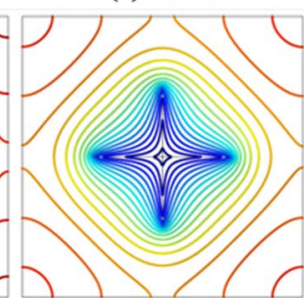

(g) $2000 \mathrm{~d}$

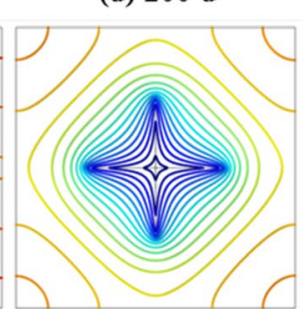

(h) $3000 \mathrm{~d}$

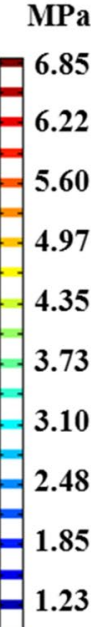

Fig. 5 Pressure contours distribution at different times

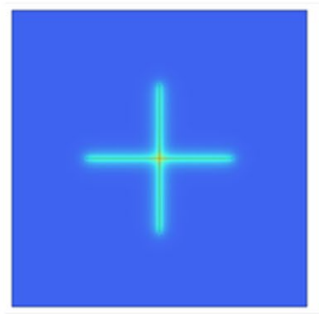

(a) $10 \mathrm{~d}$

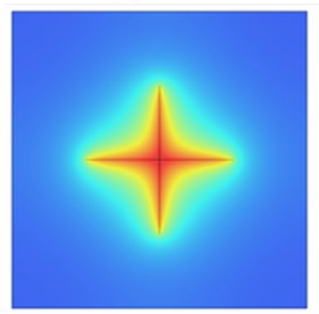

(e) $600 \mathrm{~d}$

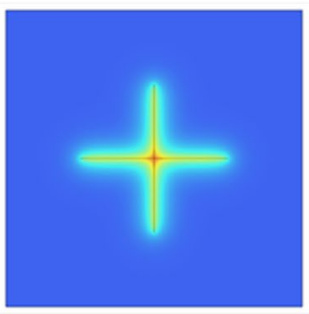

(b) $50 \mathrm{~d}$

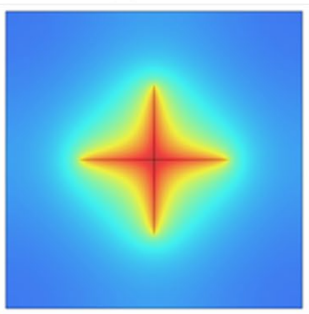

(f) $1200 \mathrm{~d}$

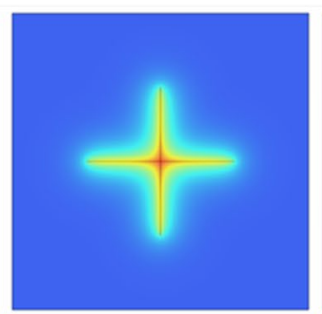

(c) $100 \mathrm{~d}$

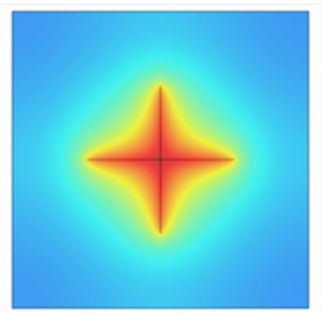

(g) $2000 \mathrm{~d}$

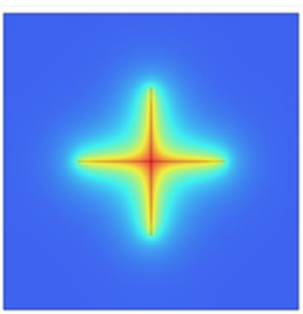

(d) $200 \mathrm{~d}$

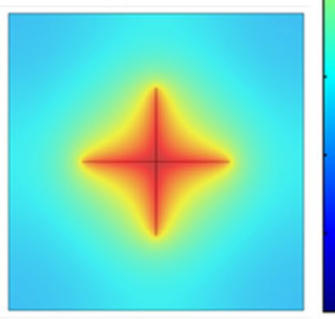

(h) $3000 \mathrm{~d}$

Fig. 6 Permeability ratio distribution at different times 


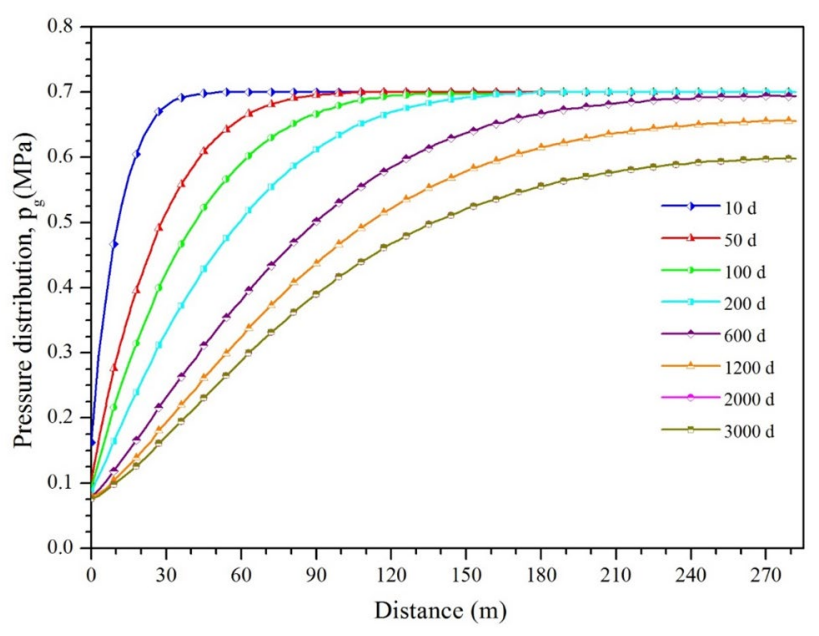

Fig. 7 Pressure distribution variation curve versus distance along line $\mathrm{OA}$ at various times

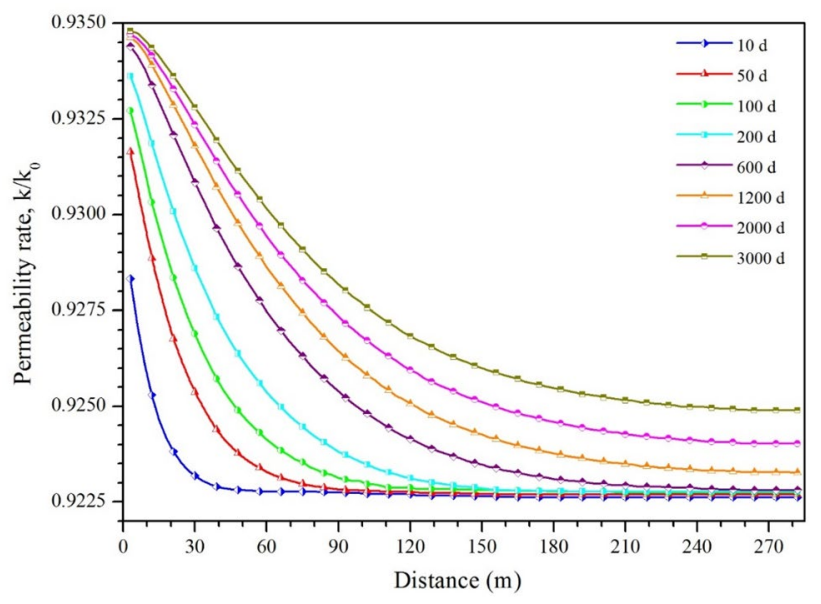

Fig. 8 Permeability ratio variation curve versus distance along line $\mathrm{OA}$ at various times

gradually with production time. There is a minimum gas pressure distribution around the multilateral well, and the pressure around the multilateral well decreases faster than the area away from the multilateral well. It can be observed from Fig. 6 that the overall permeability of coal seams increases with production time. The permeability around the multilateral well is larger than the area away from the multilateral well. This is because the gas pressure around the multilateral-well drops rapidly which leads to the gas first desorbs from the matrix around the multilateral well, causing the matrix in the corresponding area begin to shrink and the permeability gradually increases.

The pressure distribution and permeability ratio distribution along Line OA at various times are demonstrated in Figs. 7, 8, respectively. Line OA is marked in the second picture in Fig. 3, and it is along the diagonal direction along the $x y$ plane at mid-y position. It can be observed that the permeability ratio decreases with distance from reservoir center and its variation distance decreases with the extraction time. When the distance increases from 10 to $270 \mathrm{~m}$, the permeability rate decreases from 0.9253 to 0.9226 at the $10 \mathrm{~d}$, decreases from 0.9334 to 0.9228 at the $600 \mathrm{~d}$ and decreases from 0.9344 to 0.9249 at the $3000 \mathrm{~d}$. At the same distance, the permeability ratio increases with the extraction time. When the extraction time ranges from 10 to $3000 \mathrm{~d}$, the permeability ratio increases from 0.9228 to 0.9309 in the $50 \mathrm{~m}$ position, increases from 0.9227 to 0.9277 in the $100 \mathrm{~m}$ position and increases from 0.9226 to 0.9252 in the $200 \mathrm{~m}$ position.

\section{Comparisons of multilateral-well case and drainage hole case}

In this part, the coalbed methane development performance of multilateral-well Case and drainage holes Case were compared. There are three multilateral-well Cases and three drainage hole Cases for comparison. The specific results are as follows.

\section{Comparisons of base case and case 1}

In this section, effects of the four lateral wells (Base Case) and double drainage holes (Case 1) on coalbed methane development performance are studied. The pressure and permeability rate contours of gas extraction for Base Case and Case 1 at $50 \mathrm{~d}, 500 \mathrm{~d}, 1500 \mathrm{~d}$ and $3000 \mathrm{~d}$ are illustrated in Figs. 9, 10, respectively. It can be observed that the lowpressure and high-permeability region expands with time. The low-pressure and high-permeability spreads from the reservoir center to the surroundings for Base Case and from the bottom of the reservoir for Case 1. The location of the spread center depends on the location of the production well. For Base Case, the pressure difference between high pressure and low pressure is less than that of Case 1 at $3000 \mathrm{~d}$. The permeability ratio difference also has the same effect. It can be concluded that the gas extraction area of the multilateral well is wider and more uniform than that of drainage hole Case.

To figure out the gas extraction performance of multilateral well and drainage hole, the production rate and cumulative production of Base Case and Case 1 are compared, as shown in Fig. 11. Under the condition that only single-phase flow is considered, the production rate shows a downward trend, the initial production rate drops rapidly and the speed in the middle and late stages of production tends to be stable. For instance, the production rate of Base Case varies from $991.32 \mathrm{~m}^{3} / \mathrm{d}(100 \mathrm{~d}), 388.52 \mathrm{~m}^{3} / \mathrm{d}(1000 \mathrm{~d}), 293.35 \mathrm{~m}^{3} / \mathrm{d}$ $(2000 \mathrm{~d})$ to $241.99 \mathrm{~m}^{3} / \mathrm{d}(3000 \mathrm{~d})$. The production rate of the

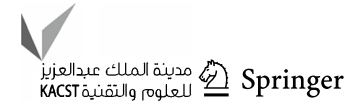



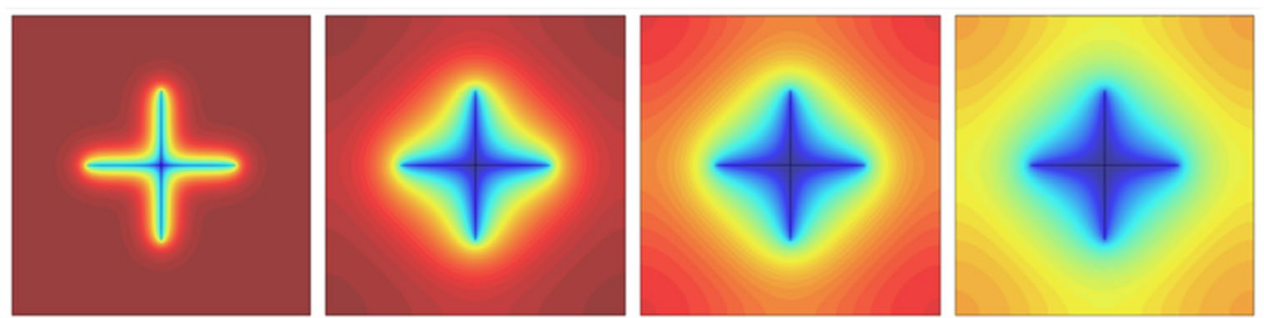

MPa

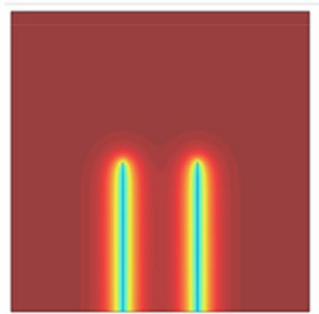

(a) $50 \mathrm{~d}$

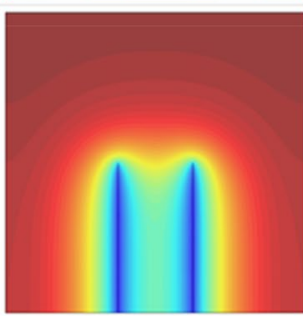

(b) $500 \mathrm{~d}$

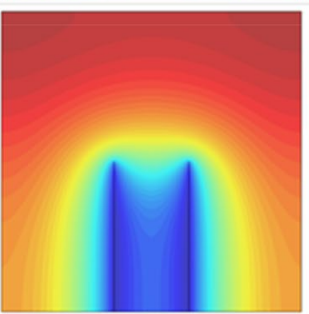

(c) $1500 \mathrm{~d}$

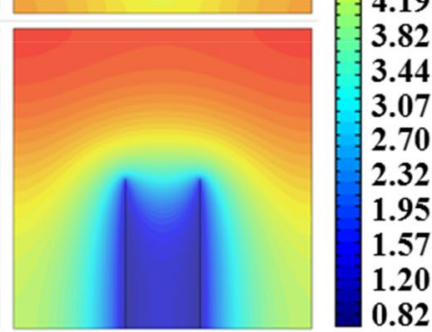

(d) $3000 \mathrm{~d}$
6.82

6.44

6.07

5.69

5.32

4.94

4.57

4.19

3.82

3.44

2.70

1.95

1.57

1.20

0.82

Fig. 9 Pressure contours of gas extraction at 50 d, 500 d, 1500 d and 3000 d (first row: Base Case, second row: Case 1)
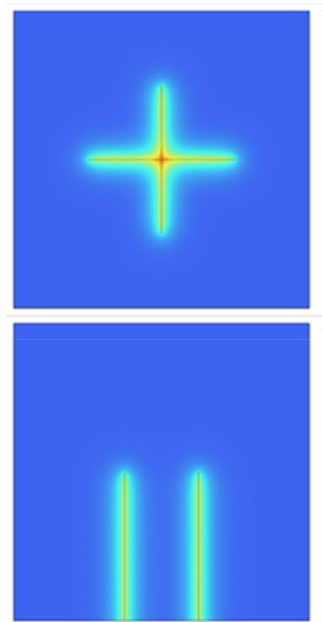

(a) $50 \mathrm{~d}$
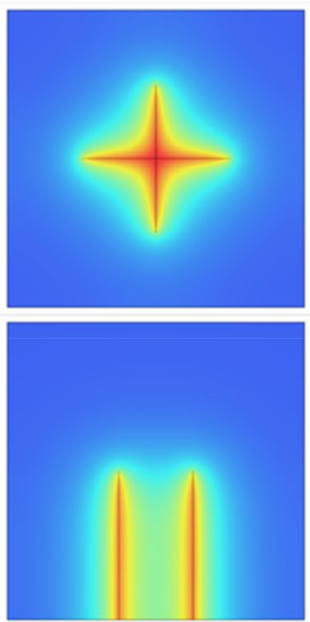

(b) $500 \mathrm{~d}$
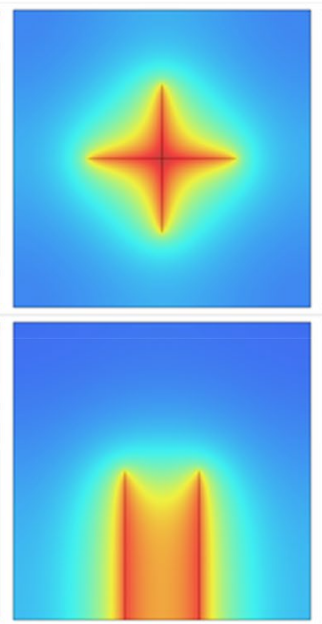

(c) $1500 \mathrm{~d}$
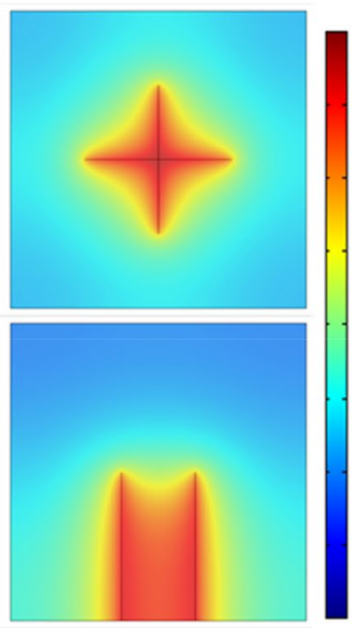

(d) $3000 \mathrm{~d}$
0.936

0.934

0.932

0.930

0.928

0.926

0.924

0.922

0.920

Fig. 10 Permeability ratio $\left(k / k_{0}\right)$ contours of gas extraction at $50 \mathrm{~d}, 500 \mathrm{~d}, 1500 \mathrm{~d}$ and $3000 \mathrm{~d}$ (first row: Base Case, second row: Case 1)

Base Case is always higher than that of Case 1. Similarly, the cumulative production of the Base Case is always higher than that of Case 1 and the ultimate cumulative production of Base Case is almost 1.27 times higher than that of Case 1.

\section{Comparisons of case 2 and case 3}

In this section, effects of the double lateral wells (Case 2) and single drainage hole (Case 3) on coalbed methane development performance are studied. The pressure and permeability ratio contours of gas extraction for Case 2 and Case 3 at $50 \mathrm{~d}, 500 \mathrm{~d}, 1500 \mathrm{~d}$ and $3000 \mathrm{~d}$ are illustrated in Fig. 12, 13 , respectively. It can be seen that the similar pressure and permeability ratio distribution effect as that of Base Case and Case 2. The low-pressure and high-permeability spreads from the reservoir center to the surroundings for Case 2 and from the bottom of the reservoir for Case 3.

Figure 14 shows the production rate and cumulative production of Case 2 and Case 3. The production rate of Case 2 varies from $579.59 \mathrm{~m}^{3} / \mathrm{d}(100 \mathrm{~d})$ to $205.51 \mathrm{~m}^{3} / \mathrm{d}(3000$ d), and Case 3 varies from $463.55 \mathrm{~m}^{3} / \mathrm{d}$ (100 d) to 145.91 $\mathrm{m}^{3} / \mathrm{d}(3000 \mathrm{~d})$. The production rate of the Case 2 is always higher than that of Case 3 . The cumulative production of Case 2 varies from $0.6261 \times 10^{5} \mathrm{~m}^{3}(100 \mathrm{~d})$ to $8.6416 \times 10^{5}$ $\mathrm{m}^{3}(3000 \mathrm{~d})$, and Case 3 varies from $0.5022 \times 10^{5} \mathrm{~m}^{3}(100$ d) to $6.4341 \times 10^{5} \mathrm{~m}^{3}(3000 \mathrm{~d})$. The ultimate cumulative 
Fig. 11 Production rate and cumulative production curve versus time for Base Case and Case 1
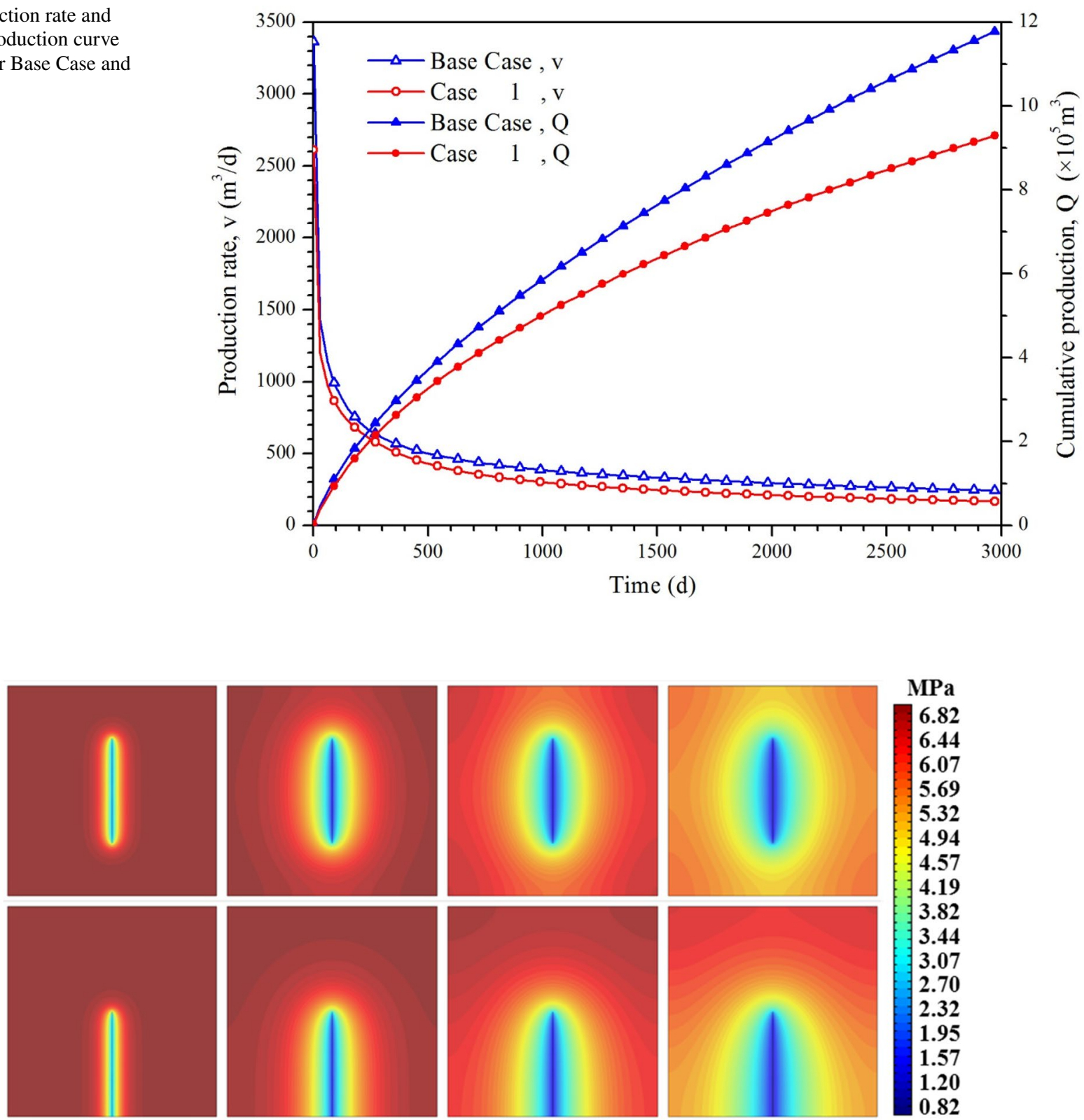

(a) $50 \mathrm{~d}$

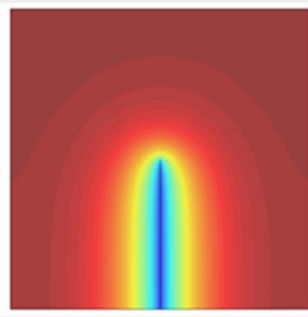

(b) $500 \mathrm{~d}$

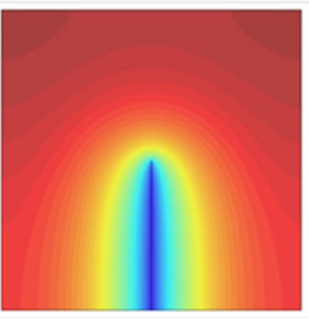

(c) $1500 \mathrm{~d}$

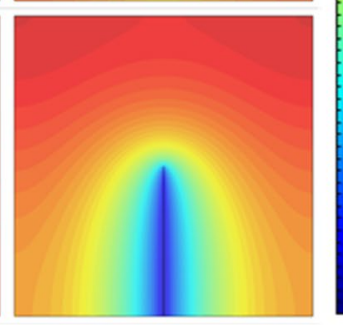

(d) $3000 \mathrm{~d}$

Fig. 12 Pressure contours of gas extraction at 50 d, 500 d, 1500 d and 3000 d (first row: Case 2, second row: Case 3)

production of Case 2 is almost 1.34 times higher than that of Case 3 at $3000 \mathrm{~d}$.

\section{Comparisons of case 4 and case 5}

In this section, effects of the six lateral wells (Case 4) and three drainage holes (Case 5) on coalbed methane development performance are studied. The pressure and permeability ratio contours of gas extraction for Case 4 and Case 5 at 50 d, 500 d, 1500 d and 3000 d are illustrated in Figs. 12, 13 , respectively. It can be seen that the similar pressure and permeability distribution effect as that of Base Case and Case 2 (Figs. 15, 16). The low-pressure and high-permeability spreads from the reservoir center to the surroundings for Case 4 and from the bottom of the reservoir for Case 5 .

Figure 17 shows the production rate and cumulative production of Case 4 and Case 5. The production rate of Case 4 varies from $1200.6 \mathrm{~m}^{3} / \mathrm{d}(100 \mathrm{~d})$ to $235.92 \mathrm{~m}^{3} / \mathrm{d}(3000$ d), and Case 5 varies from $1277.1 \mathrm{~m}^{3} / \mathrm{d}(100 \mathrm{~d})$ to 174.2 $\mathrm{m}^{3} / \mathrm{d}(3000 \mathrm{~d})$. In the first $900 \mathrm{~d}$, the production rate of Case 5 is higher than that of Case 4, while the production rate of Case 4 is higher than that of Case 5 after $900 \mathrm{~d}$. The 

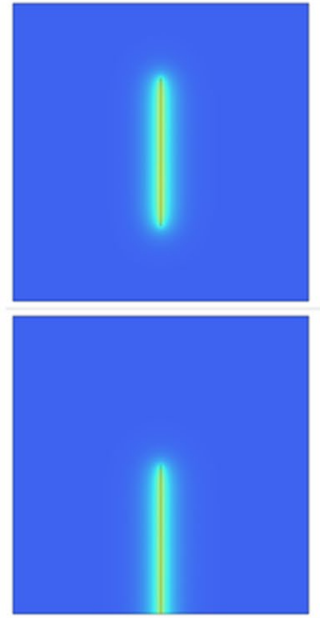

(a) $50 \mathrm{~d}$
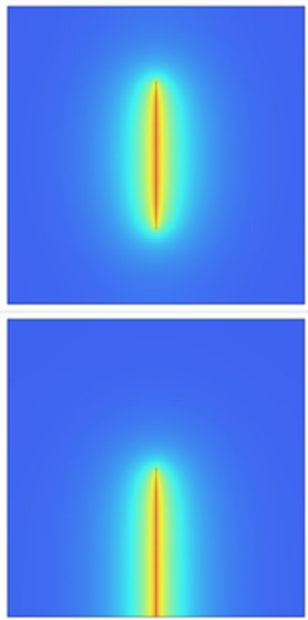

(b) $500 \mathrm{~d}$
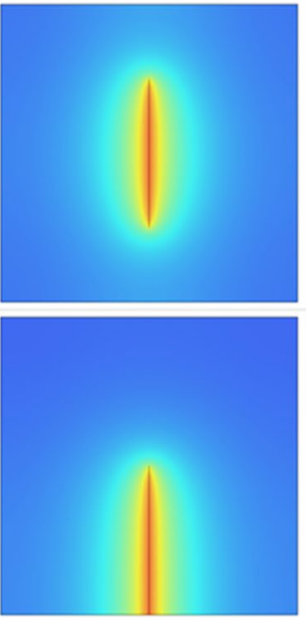

(c) $1500 \mathrm{~d}$

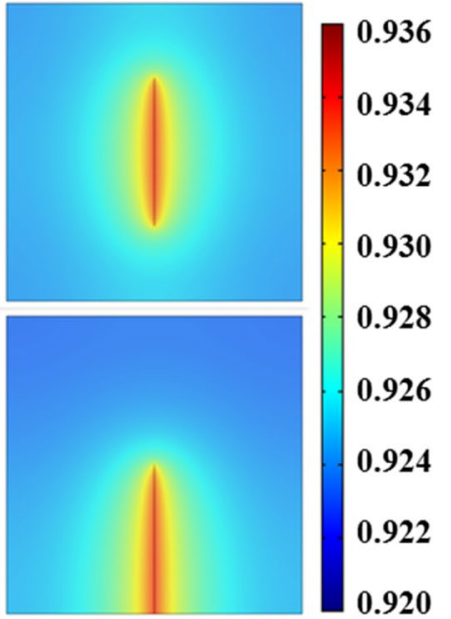

(d) $3000 \mathrm{~d}$

Fig. 13 Permeability ratio contours of gas extraction at $50 \mathrm{~d}, 500 \mathrm{~d}, 1500 \mathrm{~d}$ and $3000 \mathrm{~d}$ (first row: Case 2, second row: Case 3)

Fig. 14 Production ratio and cumulative production curve versus time for Case 2 and Case 3

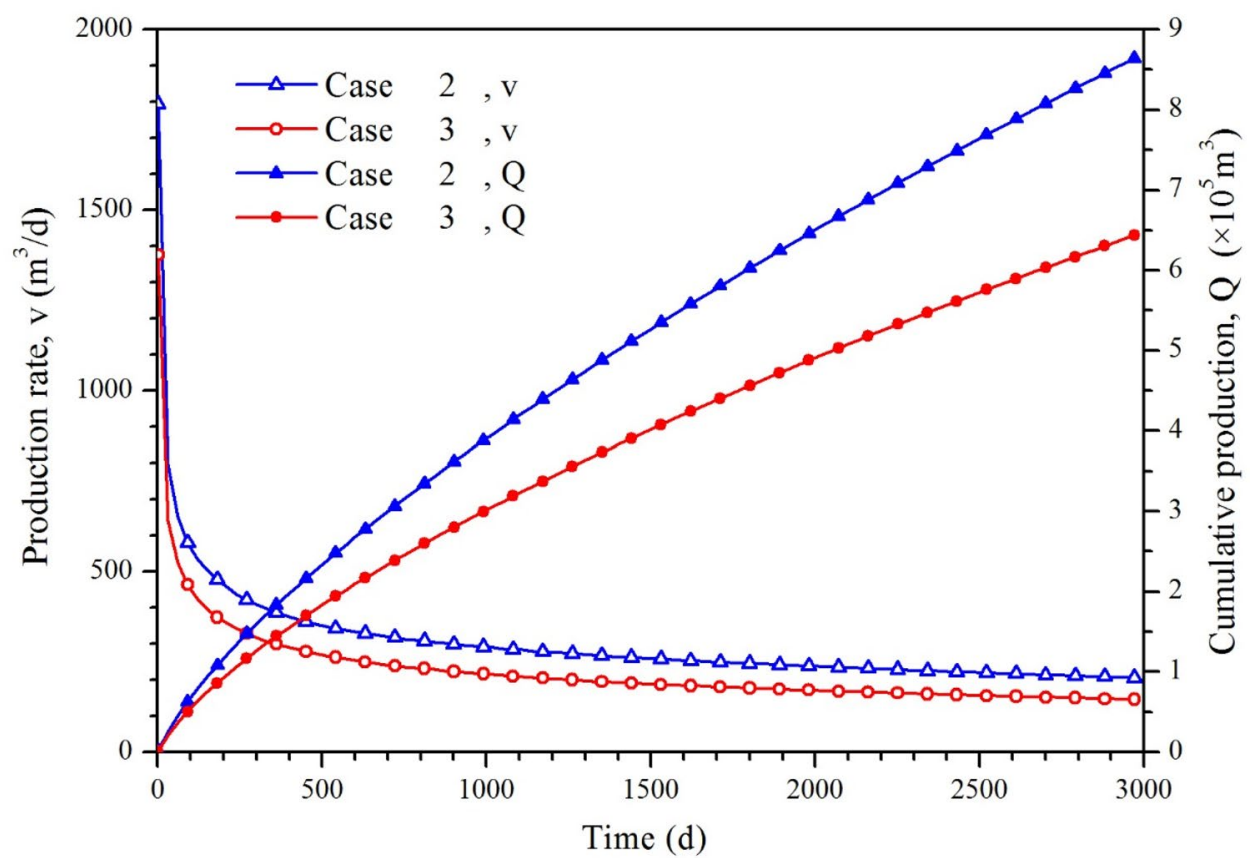

cumulative production of Case 4 varies from $1.4064 \times 10^{5}$ $\mathrm{m}^{3}(100 \mathrm{~d})$ to $12.4845 \times 10^{5} \mathrm{~m}^{3}(3000 \mathrm{~d})$ and Case 5 varies from $1.3834 \times 10^{5} \mathrm{~m}^{3}(100 \mathrm{~d})$ to $1.2179 \times 10^{6} \mathrm{~m}^{3}(3000$ d). The ultimate cumulative production of Case 4 is almost 1.025 times higher than that of Case 5 at $3000 \mathrm{~d}$.

The cumulative production statistics for Base Case and Case1-Case 5 are illustrated in Fig. 18. A comparison of the results reveals the coalbed methane development performance of multilateral-well Case is better than that of drainage holes Case. The ultimate cumulative production of four lateral wells is almost 1.27 times than that of drainage holes.
When the quantity of lateral wells increases from 2 to 6 , the cumulative production at $3000 \mathrm{~d}$ increases by a factor of 1.5 . There are two possible reasons. One is because the multilateral well located in the center of the reservoir are more stretched and have a larger area of influence. The second is that the radius of the multilateral well is larger than of the drainage hole and more gas flows into the multi-branched well.

For multilateral well, the cumulative production increases with the quantity of lateral wells. When the lateral well number is $2,4,6$, the cumulative production 

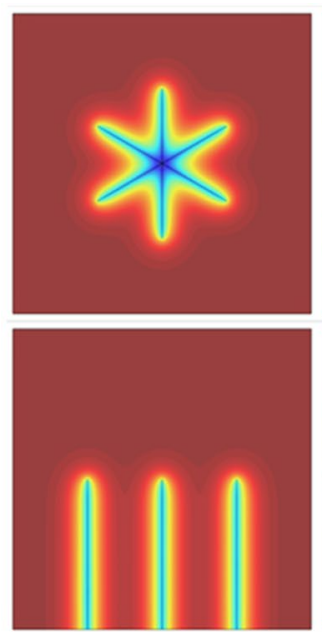

(a) $50 \mathrm{~d}$
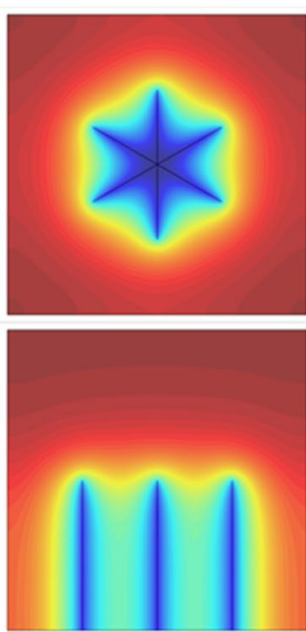

(b) $500 \mathrm{~d}$
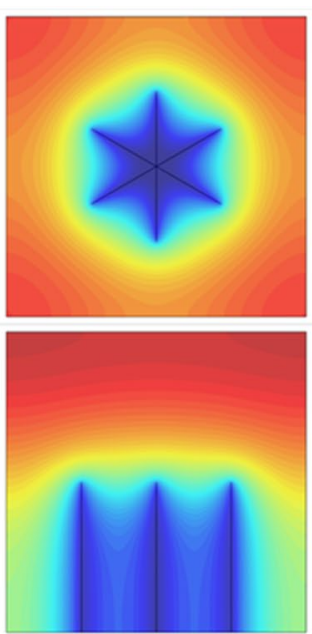

(c) $1500 \mathrm{~d}$
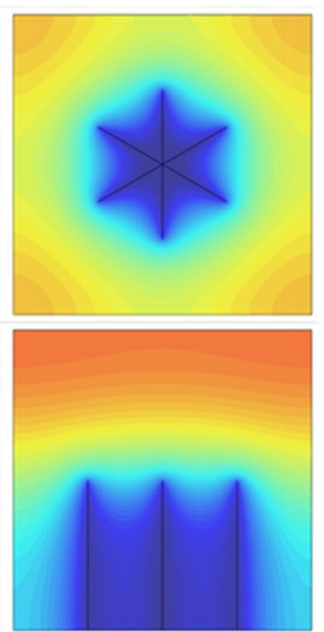

(d) $3000 \mathrm{~d}$
MPa

6.82

6.44

6.07

5.69

5.32

4.94

4.57

4.19

3.82

3.44

3.07

2.70

2.32

1.95

1.57

1.20

0.82

Fig. 15 Pressure contours of gas extraction at $50 \mathrm{~d}, 500 \mathrm{~d}, 1500 \mathrm{~d}$ and $3000 \mathrm{~d}$ (first row: Case 4, second row: Case 5)
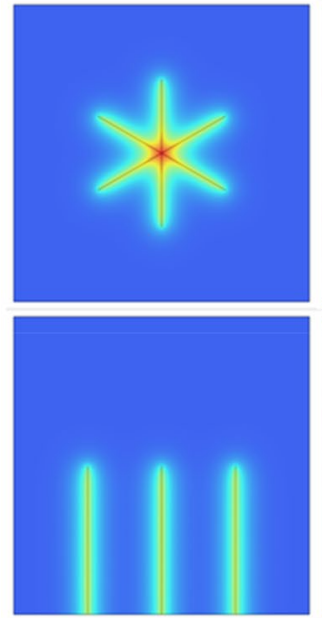

(a) $50 \mathrm{~d}$
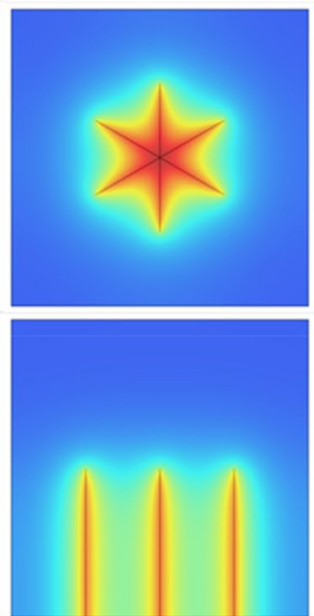

(b) $500 \mathrm{~d}$
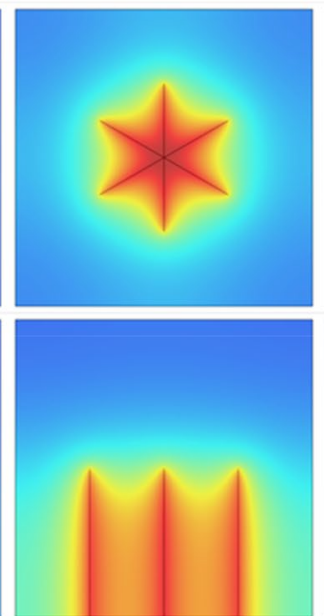

(c) $1500 \mathrm{~d}$
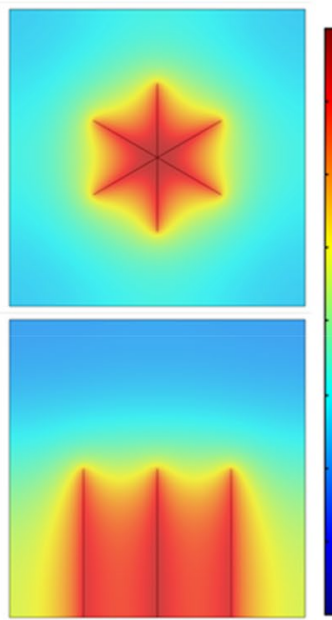

(d) $3000 \mathrm{~d}$

0.936

0.934

0.932

0.930

0.928

0.926

0.924

0.922

0.920

Fig. 16 Permeability ratio contours of gas extraction at $50 \mathrm{~d}, 500 \mathrm{~d}, 1500 \mathrm{~d}$ and $3000 \mathrm{~d}$ (first row: Case 4, second row: Case 5)

is $8.6416 \times 10^{5} \mathrm{~m}^{3}, 11.7785 \times 10^{5} \mathrm{~m}^{3}, 1.2445 \times 10^{6} \mathrm{~m}^{3}$ at $3000 \mathrm{~d}$, respectively. The cumulative production increases obvious when the lateral well number vary from 2 to 4 . It can be speculated that the coalbed methane development performance can be improved to a certain extent by increasing the quantity of lateral well.

\section{Comparisons of multilateral well with different branch length}

In this section, the length distribution of lateral wells on coalbed methane development performance are studied. Figures 19, 20 show the pressure contours and permeability ratio contours of gas extraction at $50 \mathrm{~d}, 500 \mathrm{~d}, 1500 \mathrm{~d}$ and
$3000 \mathrm{~d}$ for Case 6 and Case 7, respectively. The lateral wells of Case 6 and Case 7 are all axisymmetric, and the pressure and permeability at various times also show an axisymmetric distribution. Figures 21, 22 show the pressure contours and permeability ratio contours of gas extraction at $50 \mathrm{~d}, 500$ d, $1500 \mathrm{~d}$ and $3000 \mathrm{~d}$ for Case 8 and Case 9, respectively. The lateral wells of Case 8 and Case 9 are all diagonally symmetric and their pressure and permeability at various times also symmetrically distributed diagonally. It suggests that the length distribution of lateral wells has an effect on regional gas extraction efficiency.

In order to figure out the gas extraction performance of multilateral well with different lateral length distribution, the production rate and cumulative production of Base

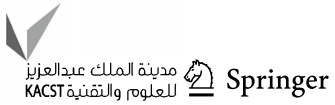


Fig. 17 Production rate and cumulative production curve versus time for Case 4 and Case 5

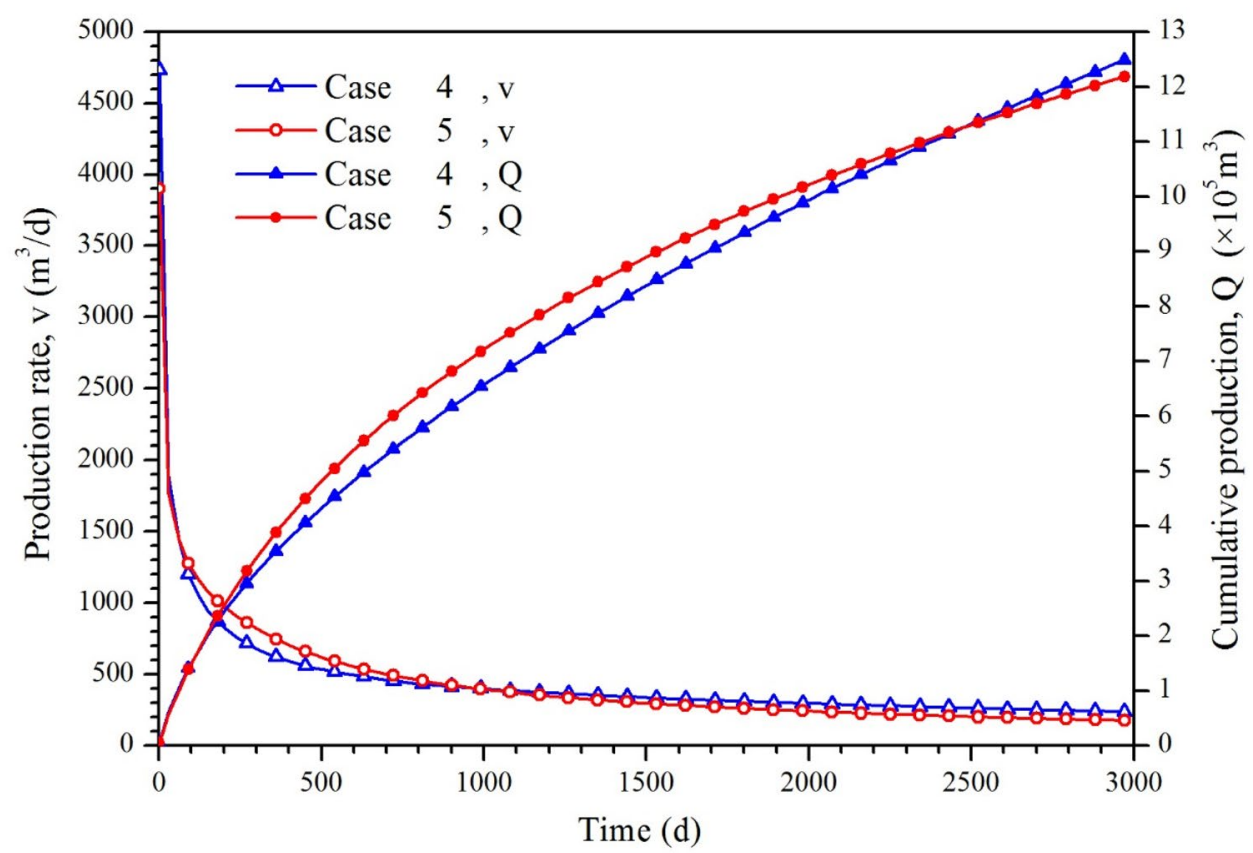

Case and Case 6-9 are compared, as shown in Fig. 23. It can be observed that when all the length of lateral wells is $100 \mathrm{~m}$, the gas production rate and cumulative production are always higher than other Cases. When the lengths of the lateral wells are not equal, the ultimate gas production from high to low is Case 6, Case 8, Case 7 and Case 9, respectively.

For Case 6 and Case 8, there are two lateral wells of length $95 \mathrm{~m}$ and $105 \mathrm{~m}$ with a maximum length difference of $10 \mathrm{~m}$. For Case 7 and Case 9, there are two lateral wells of length $90 \mathrm{~m}$ and $110 \mathrm{~m}$ with a maximum length difference of $20 \mathrm{~m}$. The gas extraction performance of Case 6 and Case 8 are better than that of Case 7 and Case 9, it can be seen

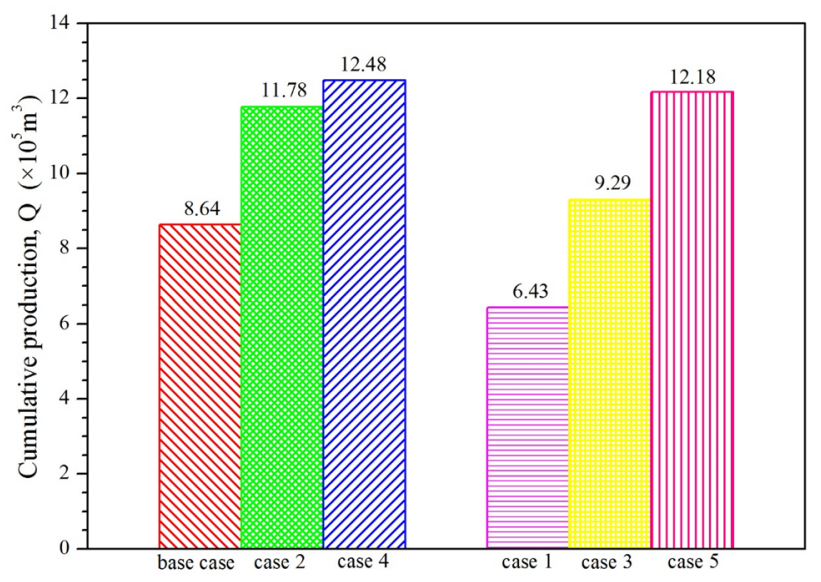

Fig. 18 Cumulative production statistics for Base Case and Case 1Case 5 that the uniform of length distribution has a positive effect on coalbed methane development. The difference between the Case 6 and Case 8 is that the lateral length distribution is different. The lateral wells of Case 6 are center-symmetrical, long lateral well and short lateral well are alternately distributed, it can produce CBM in the gas reservoir more uniformly. Therefore, the gas extraction performance of Case 6 is higher than that of Case 8 . The gas extraction performance of Case 7 and Case 9 can also explain by the symmetry of length distribution.

Overall, when the total length of lateral wells is equal, the uniformity and symmetry of lateral length distribution are two key factors on the gas extraction performance. Under the simulation condition in this paper, the uniformity of lateral length distribution has a greater impact on the gas extraction performance than that of symmetry.

\section{Comparisons of multilateral well with different intersection angle}

In this section, the intersection angle of lateral wells on coalbed methane development performance are studied. Figures 24, 25 show the pressure contours of gas extraction at $50 \mathrm{~d}, 500 \mathrm{~d}, 1500 \mathrm{~d}$ and $3000 \mathrm{~d}$ for Case 10-11 and Case $12-13$, respectively. Figures 26, 27 show the permeability ratio contours of gas extraction at $50 \mathrm{~d}, 500 \mathrm{~d}, 1500 \mathrm{~d}$ and $3000 \mathrm{~d}$ for Case 10-11 and Case 12-13, respectively. It can be observed that the pressure and permeability distribution difference induced by different intersection angle of lateral wells. 

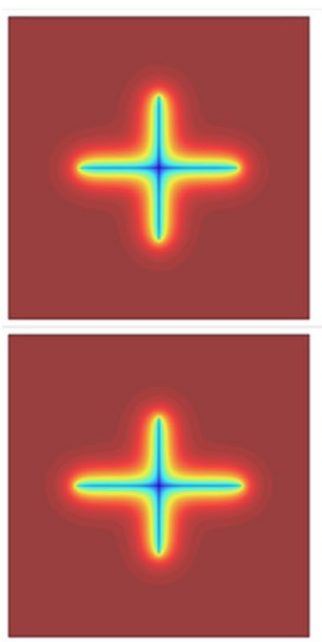

(a) $50 \mathrm{~d}$
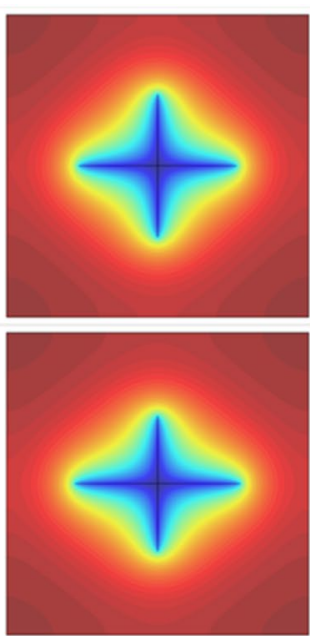

(b) $500 \mathrm{~d}$
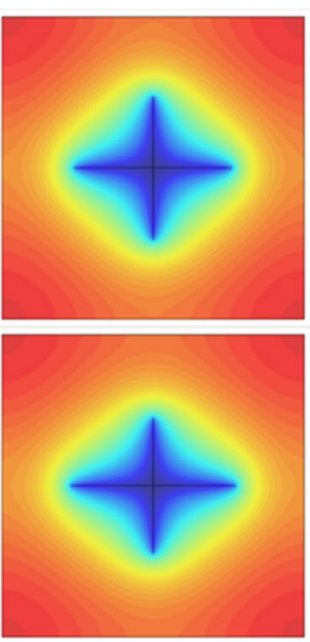

(c) $1500 \mathrm{~d}$
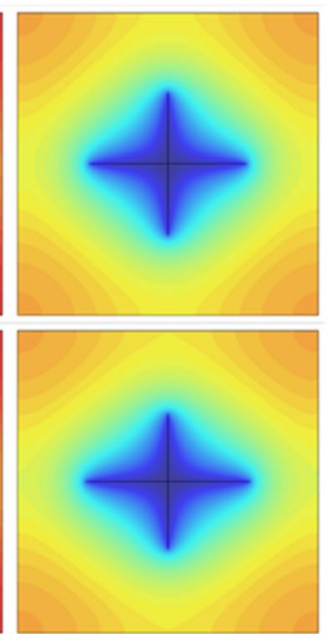

(d) $3000 \mathrm{~d}$

MPa

6.82

6.44

6.07

5.69

5.32

4.94

4.57

4.19

3.82

3.44

3.07

2.70

2.32

1.95

1.57

1.20

0.82

Fig. 19 Pressure contours of gas extraction at $50 \mathrm{~d}, 500 \mathrm{~d}, 1500 \mathrm{~d}$ and $3000 \mathrm{~d}$ (first row: Case 6, second row: Case 7)
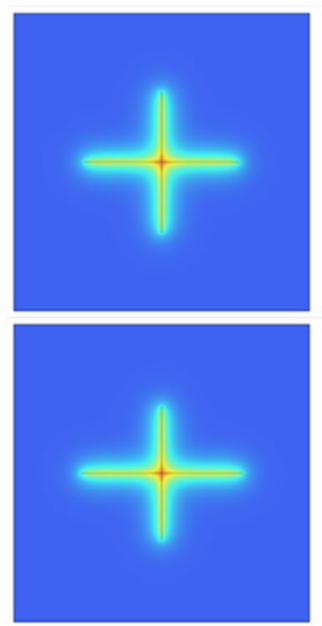

(a) $50 \mathrm{~d}$
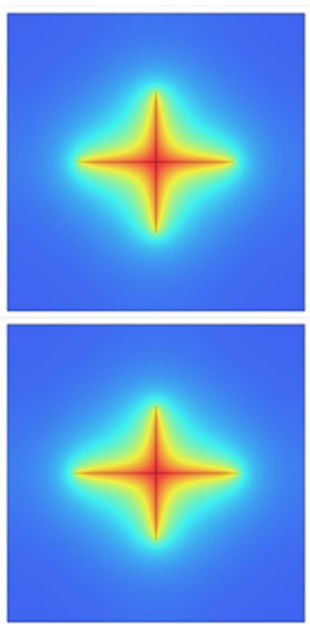

(b) $500 \mathrm{~d}$
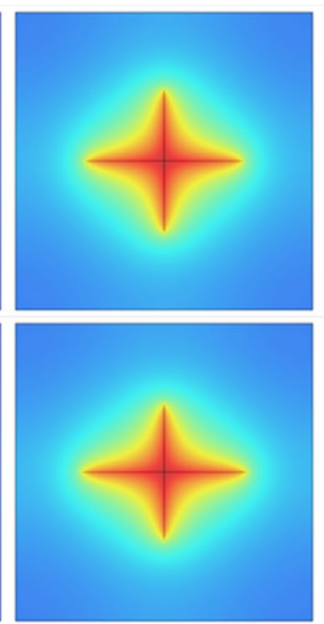

(c) $1500 \mathrm{~d}$
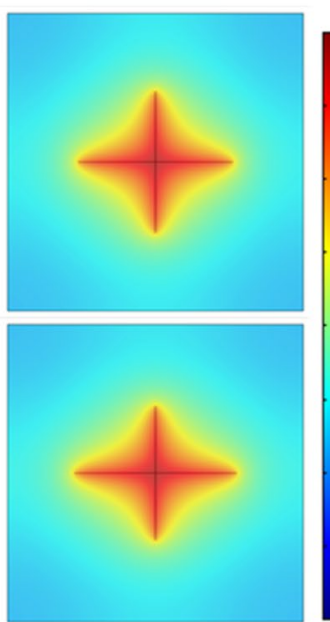

(d) $3000 \mathrm{~d}$
0.936

0.934

0.932

0.930

0.928

0.926

0.924

0.922

0.920

Fig. 20 Permeability ratio contours of gas extraction at $50 \mathrm{~d}, 500 \mathrm{~d}, 1500 \mathrm{~d}$ and $3000 \mathrm{~d}$ (first row: Case 6, second row: Case 7)

Figure 26 shows the production rate and cumulative production of Base Case and Case 10-13. When the intersection angle varies from $90^{\circ}$ to $50^{\circ}$, the ultimate cumulative production decrease from $1.1779 \times 10^{6} \mathrm{~m}^{3}\left(90^{\circ}\right)$, $1.1464 \times 10^{6} \mathrm{~m}^{3}\left(80^{\circ}\right), 1.1360 \times 10^{6} \mathrm{~m}^{3}\left(70^{\circ}\right), 1.1259 \times 10^{5}$ $\mathrm{m}^{3}\left(60^{\circ}\right)$ to $1.1086 \times 10^{6} \mathrm{~m}^{3}\left(50^{\circ}\right)$ at $3000 \mathrm{~d}$. It can be observed that the minimum intersection angle has a positive effect on cumulative production as shown in Fig. 28. This is because when the intersection angle varies from $90^{\circ}$ to $50^{\circ}$, the quadrilateral area with the lateral well as the diagonal decreases gradually. The smaller the quadrilateral area, the smaller the influence range of the multilateral well and the worse the gas extraction effect. When the intersection angle of the multilateral well is set as $90^{\circ}$, the wells are more stretched and the quadrilateral area is larger than other Cases. Overall, the optimal intersection angle is $90^{\circ}$ for the multilateral well under the simulation condition in this paper. 

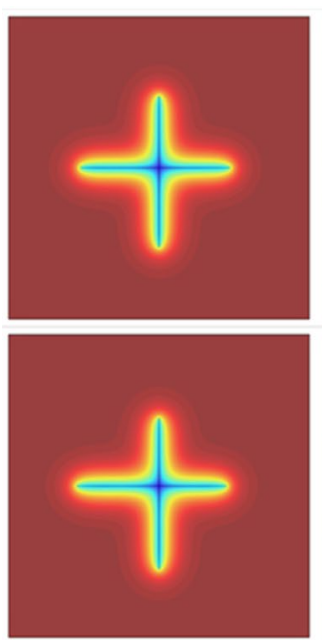

(a) $50 \mathrm{~d}$
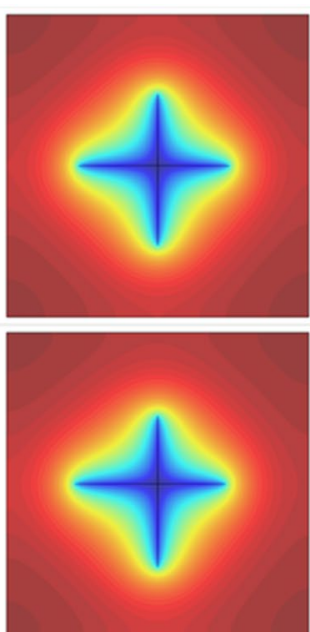

(b) $500 \mathrm{~d}$
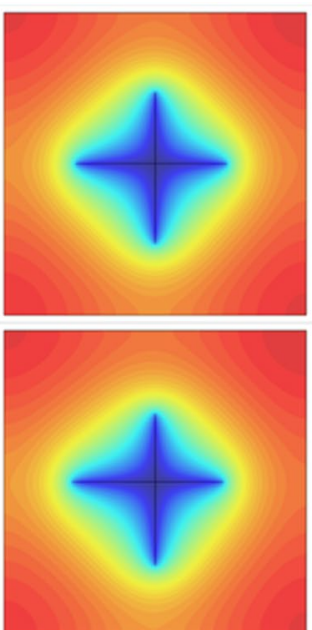

(c) $1500 \mathrm{~d}$
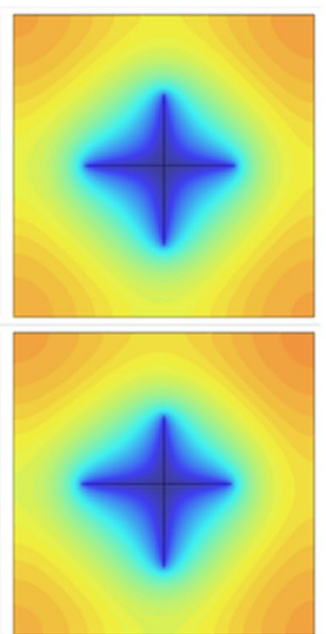

(d) $3000 \mathrm{~d}$
MPa

6.82

6.44

6.07

5.69

5.32

4.94

4.57

4.19

3.82

3.44

3.07

2.70

2.32

1.95

1.57

1.20

0.82

Fig. 21 Pressure contours of gas extraction at $50 \mathrm{~d}, 500 \mathrm{~d}, 1500 \mathrm{~d}$ and $3000 \mathrm{~d}$ (first row: Case 8, second row: Case 9)
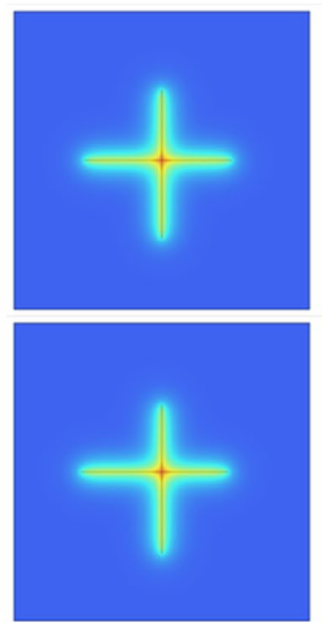

(a) $50 \mathrm{~d}$
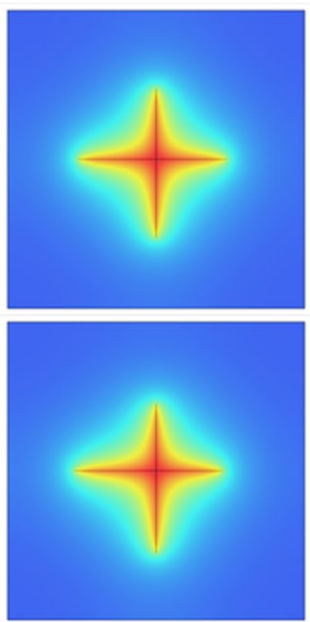

(b) $500 \mathrm{~d}$
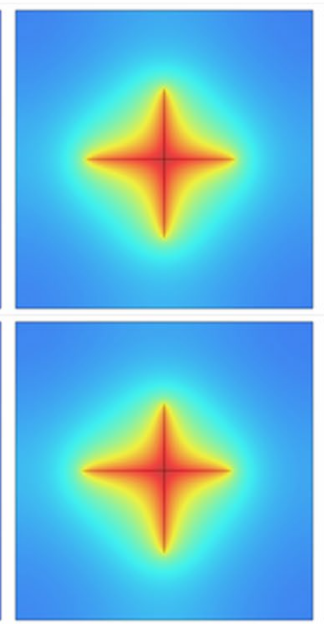

(c) $1500 \mathrm{~d}$
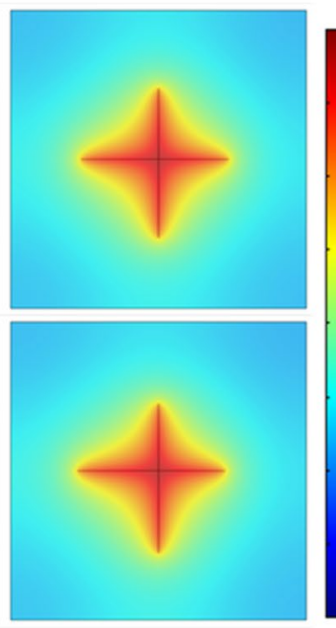

(d) $3000 \mathrm{~d}$

0.936

0.934

0.932

0.930

0.928

0.926

0.924

0.922

0.920

Fig. 22 Permeability ratio contours of gas extraction at 50 d, 500 d, 1500 d and $3000 \mathrm{~d}$ (first row: Case 8, second row: Case 9)

\section{Conclusion}

In this paper, a novel multilateral well for coalbed methane extraction was proposed. In the multilateral-well system, there is a main wellbore at the longitudinal center of coal seam and four lateral wells at the horizontal center. The coalbed methane development performance of multilateral-well Case is better than that of traditional drainage holes. A hydraulic-mechanical coupling model was established for the novel multilateral-well system. Based on the model, the pressure distribution and permeability distribution of the gas extraction process with multilateral well were analyzed comprehensively. Subsequently, the gas extraction performance with multilateral well and drainage holes were compared. The number, length distribution and intersection angle of multilateral-well system on the gas extraction performance were investigated. The key findings of the study were as follows. 
Fig. 23 Production rate and cumulative production curve versus time for Base Case, Case 6, Case 7, Case 8 and Case 9
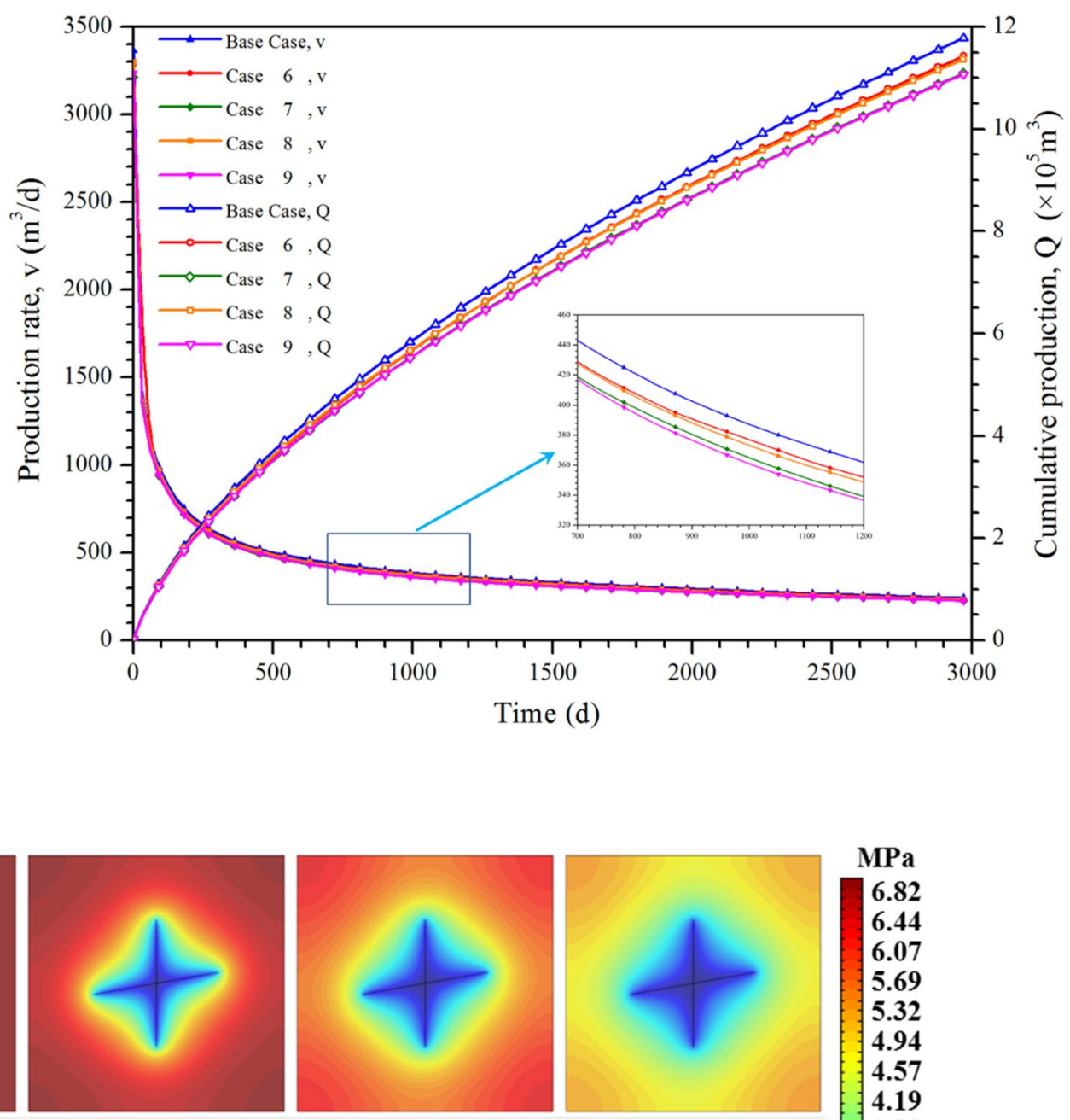

0.82

(d) 3000 d

(b) $500 \mathrm{~d}$

(c) $1500 \mathrm{~d}$

(a) $50 \mathrm{~d}$

Fig. 24 Pressure contours of gas extraction at 50 d, 500 d, 1500 d and 3000 d (first row: Base Case, second row: Case 10, third row: Case 11)

(1) There is a minimum gas pressure distribution around the multilateral well and the pressure around the multilateral well decreases faster than the area away from the multilateral well. The overall permeability of coal seams increases with production time and the permeability around the multilateral well is larger than the area away from the multilateral well. This is because the gas pressure around the multilateral-well drops rapidly which leads to the gas first desorbs from the matrix around the multilateral well, causing the matrix in the corresponding area begin to shrink and the permeability gradually increases.

(2) The coalbed methane development performance of multilateral-well Case is better than that of drainage 

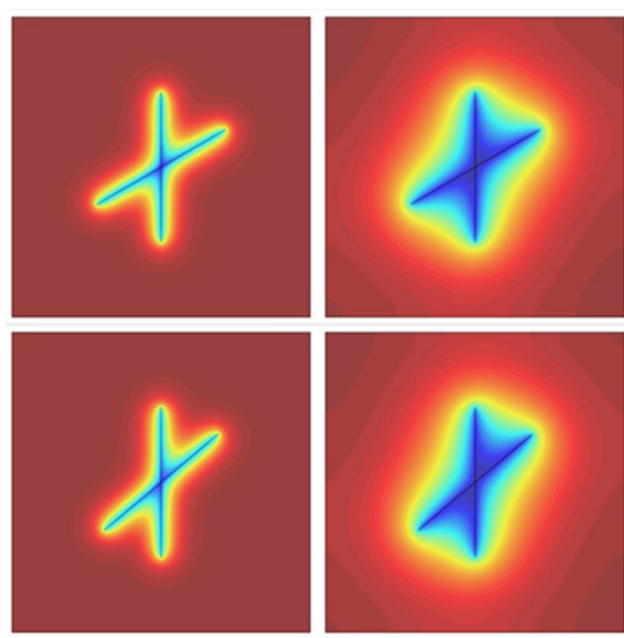

(a) $50 \mathrm{~d}$

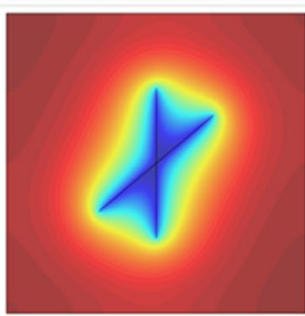

(b) $500 \mathrm{~d}$
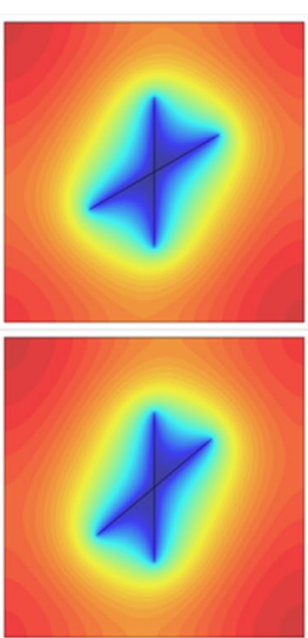

(c) $1500 \mathrm{~d}$
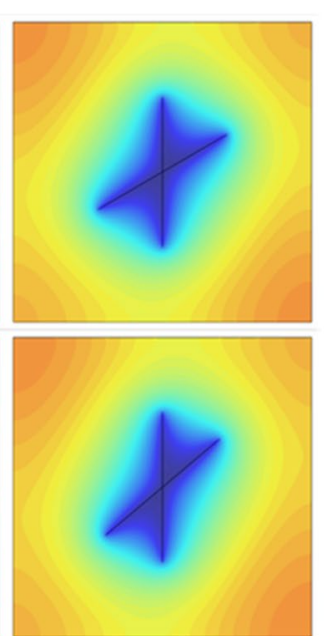

(d) $3000 \mathrm{~d}$
MPa

6.82

6.44

6.07

5.69

5.32

4.94

4.57

4.19

3.82

3.44

3.07

2.70

2.32

1.95

1.57

1.20

0.82

Fig. 25 Pressure contours of gas extraction at 50 d, 500 d, 1500 d and 3000 d (first row: Base Case, second row: Case 12, third row: Case 13)
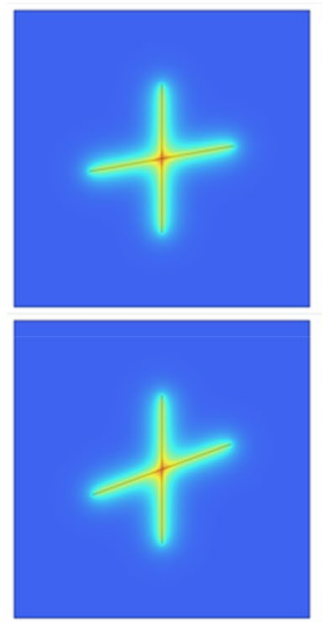

(a) $50 \mathrm{~d}$
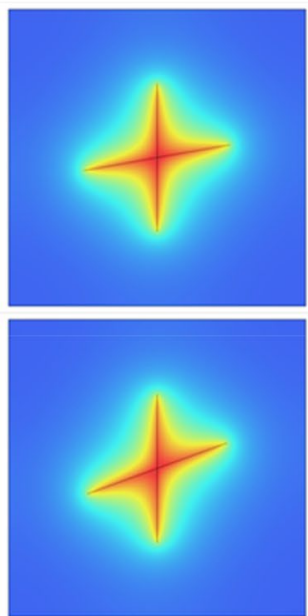

(b) $500 \mathrm{~d}$
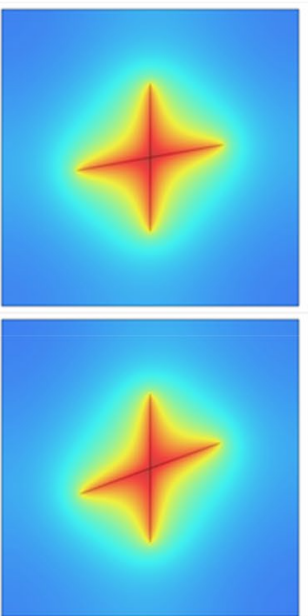

(c) $1500 \mathrm{~d}$
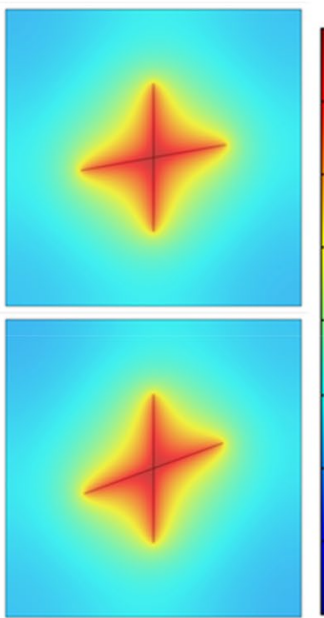

(d) $3000 \mathrm{~d}$

0.936

0.934

0.932

0.930

0.928

0.926

0.924

0.922

0.920

Fig. 26 Permeability ratio contours of gas extraction at $50 \mathrm{~d}, 500 \mathrm{~d}, 1500 \mathrm{~d}$ and $3000 \mathrm{~d}$ (first row: Case 10, second row: Case 11)

holes Case. The ultimate cumulative production of four lateral wells is almost 1.27 times than that of drainage holes. This is because the multilateral well located in the center of the reservoir are more stretched and have a larger area of influence. Besides, the radius of the multilateral well is larger than of the drainage hole and more gas flows into the multi-branched well.
(3) The coalbed methane development performance can be improved to a certain extent by increasing the quantity of lateral well. When the quantity of lateral wells increases from 2 to 6 , the cumulative production at $3000 \mathrm{~d}$ increases by a factor of 1.5 .

(4) When the total length of lateral wells is equal, the uniformity and symmetry of lateral length distribution are two key factors on the gas extraction performance. 

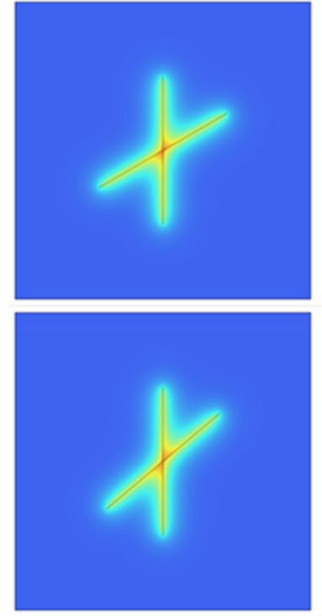

(a) $50 \mathrm{~d}$
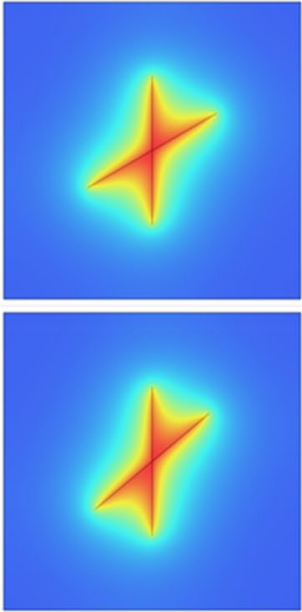

(b) $500 \mathrm{~d}$

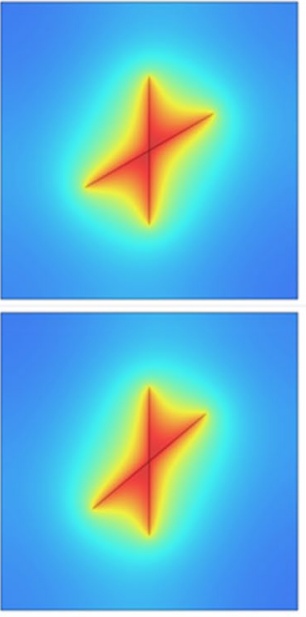

(c) $1500 \mathrm{~d}$

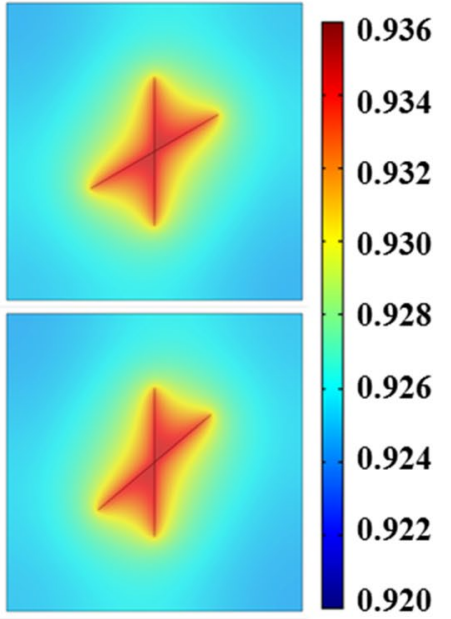

(d) $3000 \mathrm{~d}$

Fig. 27 Permeability ratio contours of gas extraction at $50 \mathrm{~d}, 500 \mathrm{~d}, 1500 \mathrm{~d}$ and $3000 \mathrm{~d}$ (first row: Case 12, second row: Case 13)

Fig. 28 Production rate and cumulative production curve versus time for Base Case, Case 10 and Case 11

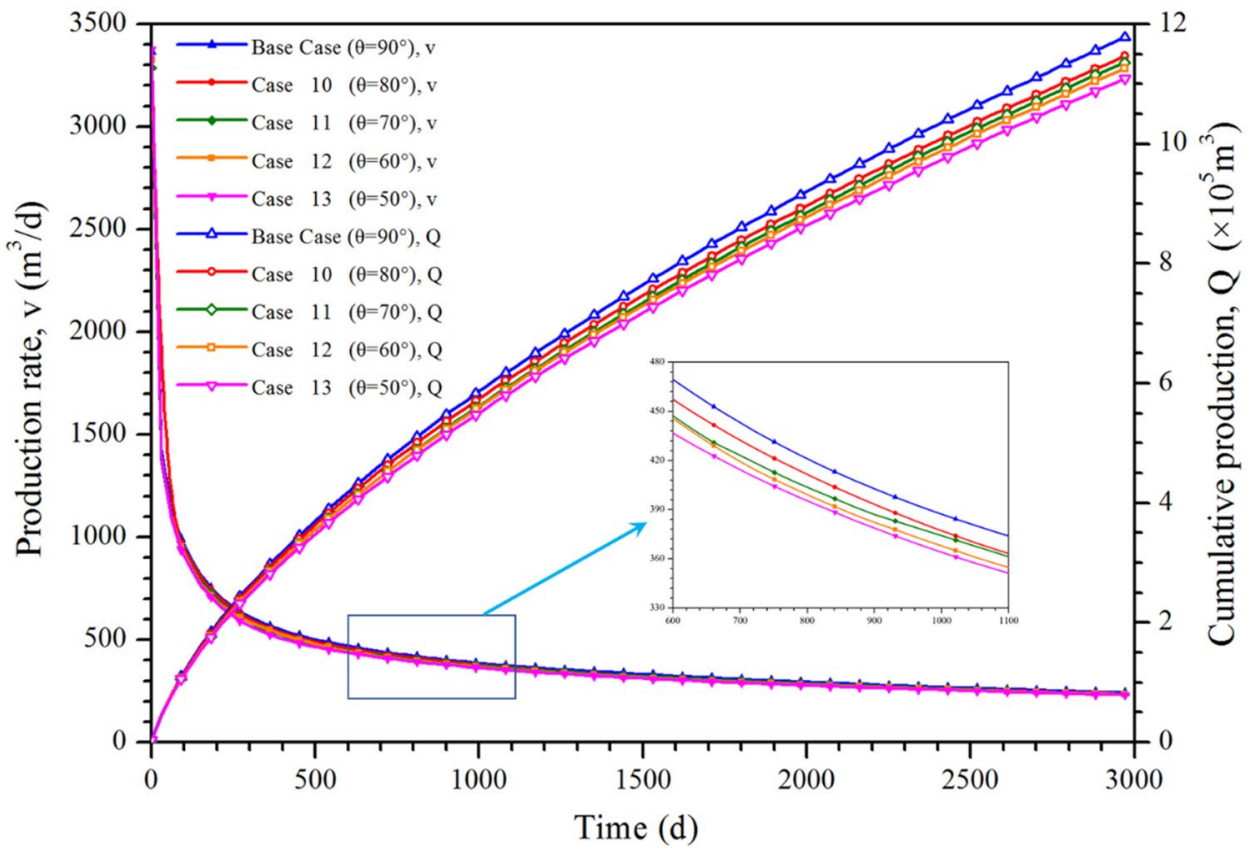

Under the simulation condition in this paper, the uniformity of lateral length distribution has a greater impact on the gas extraction performance than that of symmetry.

(5) The minimum intersection angle has a positive effect on cumulative production. When the intersection angle varies from $90^{\circ}$ to $50^{\circ}$, the cumulative production varies from $1.1779 \times 10^{6} \mathrm{~m}^{3}$ to $1.1086 \times 10^{6} \mathrm{~m}^{3}$. Under the simulation condition in this paper, the optimal intersection angle is $90^{\circ}$ for the multilateral well.
Acknowledgements This work was supported by the National Natural Science Foundation of China (51474070). The authors would like to express sincere appreciation to the editor and the anonymous reviewers for their helpful comments on the paper.

Funding This work was supported by the National Natural Science Foundation of China (51474070).

Open Access This article is licensed under a Creative Commons Attribution 4.0 International License, which permits use, sharing, adaptation, distribution and reproduction in any medium or format, as long as you give appropriate credit to the original author(s) and the source, provide a link to the Creative Commons licence, and indicate if changes 
were made. The images or other third party material in this article are included in the article's Creative Commons licence, unless indicated otherwise in a credit line to the material. If material is not included in the article's Creative Commons licence and your intended use is not permitted by statutory regulation or exceeds the permitted use, you will need to obtain permission directly from the copyright holder. To view a copy of this licence, visit http://creativecommons.org/licenses/by/4.0/.

\section{References}

An H, Wei XR, Wang GX, Massarotto P, Wang FY, Rudolph V, Golding SD (2015) Modeling anisotropic permeability of coal and its effects on $\mathrm{CO}_{2}$ sequestration and enhanced coalbed methane recovery. Int J Coal Geol 152:15-24. https://doi.org/10.1016/j. coal.2015.09.013

Chen XX, Wang L, Xue L (2019a) A gaseous compound of hydrogen and carbon production performance model in coalbed reservoir with horizontal fractures. Int J Hydrogen Energ 44(11):52625269. https://doi.org/10.1016/j.ijhydene.2018.08.081

Chen ZM, Liao XW, Zhao XL (2019b) A practical methodology for production-data analysis of single-phase unconventional wells with complex fracture geometry. SPE Reserv Eval Eng 22(02):458-476. https://doi.org/10.2118/191372-PA

Cui X, Bustin RM (2005) Volumetric strain associated with methane desorption and its impact on coalbed gas production from deep coal seams. Aapg Bull 89(9):1181-1202. https://doi. org/10.1306/05110504114

Fan L, Liu SM (2018) Numerical prediction of in situ horizontal stress evolution in coalbed methane reservoirs by considering both poroelastic and sorption induced strain effects. Int $\mathrm{J}$ Rock Mech Min 104:156-164. https://doi.org/10.1016/j.ijrmm s.2018.02.012

Fan CJ, Elsworth D, Li S, Zhou LJ, Yang ZH, Song Y (2019) Thermohydro-mechanical-chemical couplings controlling $\mathrm{CH}_{4}$ production and $\mathrm{CO}_{2}$ sequestration in enhanced coalbed methane recovery. Energy 173:1054-1077. https://doi.org/10.1016/j.energ y.2019.02.126

Feng RM, Liu J, Chen SN, Bryant S (2018) Effect of gas compressibility on permeability measurement in coalbed methane formations: experimental investigation and flow modeling. Int J Coal Geol 198:144-155. https://doi.org/10.1016/j.coal.2018.09.010

Li T, Wu CF, Liu Q (2015) Characteristics of coal fractures and the influence of coal facies on coalbed methane productivity in the South Yanchuan Block, China. J Nat Gas Sci Eng 22:625-632. https://doi.org/10.1016/j.jngse.2015.01.014

Li S, Fan CJ, Han J, Luo MK, Yang ZH, Bi HJ (2016) A fully coupled thermal-hydraulic-mechanical model with two-phase flow for coalbed methane extraction. J Nat Gas Sci Eng 33:324-336. https://doi.org/10.1016/j.jngse.2016.05.032

Li MH, Liu GF, Liu XR, Li ZJ, Zhang Q, Shen BX (2019) Performance of a direct-injection natural gas engine with multiple injection strategies. Energy 2019:116363. https://doi.org/10.1016/j.energ y.2019.116363

Liu HH, Sang SX, Formolo M, Li MX, Liu SQ, Xu HJ, An SK, Li JJ, Wang XZ (2013) Production characteristics and drainage optimization of coalbed methane wells: a case study from lowpermeability anthracite hosted reservoirs in southern Qinshui Basin China. Energy Sustain Dev 17(5):412-423. https://doi. org/10.1016/j.esd.2013.04.005

Liu ZD, Cheng YP, Liu QQ, Jiang JY, Li W, Zhang KZ (2017a) Numerical assessment of CMM drainage in the remote unloaded coal body: insights of geostress-relief gas migration and coal permeability. J Nat Gas Sci Eng 45:487-501. https://doi.org/10.1016/j. jngse.2017.06.017
Liu T, Lin BQ, Yang W, Liu T, Kong J, Huang ZB, Wang R, Zhao Y (2017b) Dynamic diffusion-based multifield coupling model for gas drainage. J Nat Gas Sci Eng 44:233-249. https://doi. org/10.1016/j.jngse.2017.04.026

Liu T, Lin BQ, Yang W, Zhai C, Liu T (2017c) Coal permeability evolution and gas migration under non-equilibrium state. Transport Porous Med 118(3):393-416. https://doi.org/10.1007/s1124 2-017-0862-8

Liu HH, Sang SX, Xue JH, Lan TH, Xu HJ, Ren B, Liu SQ (2018) Evolution and geochemical characteristics of gas phase fluid and its response to inter-well interference during multi-well drainage of coalbed methane. J Petrol Sci Eng 162:491-501. https://doi. org/10.1016/j.petrol.2017.10.007

Luo DK, Dai YJ, Xia LY (2011) Economic evaluation based policy analysis for coalbed methane industry in China. Energy 36(1):360-368. https://doi.org/10.1016/j.energy.2010.10.031

Luo CJ, Zhang DF, Lun ZM, Zhao CP, Wang HT, Pan ZJ, Li YH, Zhang J, Jia SQ (2019) Displacement behaviors of adsorbed coalbed methane on coals by injection of $\mathrm{SO}_{2} / \mathrm{CO}_{2}$ binary mixture. Fuel 247:356-367. https://doi.org/10.1016/j.fuel.2019.03.057

Ma YY, Li SB, Zhang LG, Liu SZ, Liu ZY, Li H, Shi EX, Zhang HJ (2020a) Numerical simulation study on the heat extraction performance of multi-well injection enhanced geothermal system. Renew Energ 151:782-792. https://doi.org/10.1016/j.renen e.2019.11.067

Ma YY, Li SB, Zhang LG, Liu SZ, Liu ZY, Li H, Shi EX (2020b) Study on the effect of well layout schemes and fracture parameters on the heat extraction performance of enhanced geothermal system in fractured reservoir. Energy 202:117811. https://doi. org/10.1016/j.energy.2020.117811

Mohammed N, Abbas AJ, Enyi GC, Suleiman SM, Edem DE, Abba $M$ (2020) Alternating $\mathrm{N}_{2}$ gas injection as a potential technique for enhanced gas recovery and $\mathrm{CO}_{2}$ storage in consolidated rocks: an experimental study. J Petrol Explor Prod Technol 10:3883-3903. https://doi.org/10.1007/s13202-020-00935-z

Moore R, Palmer I, Higgs N (2015) Anisotropic model for permeability change in coalbed-methane wells. SPE Reserv Eval Eng 18(04):456-462. https://doi.org/10.2118/169592-PA

Mu FY, Zhong WZ, Zhao XL, Che CB, Chen YP, Zhu J, Wang B (2015) Strategies for the development of CBM gas industry in China. Nat Gas Ind B 2(4):383-389. https://doi.org/10.1016/j. ngib.2015.09.013

Prabu V, Mallick N (2015) Coalbed methane with $\mathrm{CO}_{2}$ sequestration: an emerging clean coal technology in India. Renew Sust Energ Rev 50:229-244. https://doi.org/10.1016/j.rser.2015.05.010

Qin Y, Moore TA, Shen J, Yang ZB, Shen YL, Wang J (2018) Resources and geology of coalbed methane in China: a review. Int Geol Rev 60(5-6):777-812. https://doi.org/10.1080/00206 814.2017.1408034

Shi JT, Hou CH, Wang S, Xiong XY, Wu SG, Liu C (2019) The semi-analytical productivity equations for vertically fractured coalbed methane wells considering pressure propagation process, variable mass flow, and fracture conductivity decrease. J Petrol Sci Eng 178:528-543. https://doi.org/10.1016/j.petro 1.2019.03.047

Sun Z, Shi JT, Wu KL, Zhang T, Feng D, Li XF (2019) Effect of pressure-propagation behavior on production performance: implication for advancing low-permeability coalbed-methane recovery. SPE J 24(02):681-697. https://doi.org/10.2118/194021-PA

Talapatra A (2020) A study on the carbon dioxide injection into coal seam aiming at enhancing coal bed methane (ECBM) recovery. J Petrol Explor Prod Technol 10:1965-1981. https://doi. org/10.1007/s13202-020-00847-y

Talapatra A, Karim MM (2020) The influence of moisture content on coal deformation and coal permeability during coalbed methane 
(CBM) production in wet reservoirs. J Petrol Explor Prod Technol 10:1907-1920. https://doi.org/10.1007/s13202-020-00880-x

Uddin N, Blommerde M, Taplin R, Laurence D (2015) Sustainable development outcomes of coal mine methane clean development mechanism projects in China. Renew Sust Energ Rev 45:1-9. https://doi.org/10.1016/j.rser.2015.01.053

Vishal V, Singh L, Pradhan SP, Singh TN, Ranjith PG (2013) Numerical modeling of Gondwana coal seams in India as coalbed methane reservoirs substituted for carbon dioxide sequestration. Energy 49:384-394. https://doi.org/10.1016/j.energy.2012.09.045

Wang G, Qin Y, Xie YW, Shen J, Zhao L, Huang B, Zhao WQ (2018) Coalbed methane system potential evaluation and favourable area prediction of Gujiao blocks, Xishan coalfield, based on multi-level fuzzy mathematical analysis. J Petrol Sci Eng 160:136-151. https ://doi.org/10.1016/j.petrol.2017.10.042

Wei YC, Li C, Cao DY, Wang AM, Zhang AX, Yao Z (2019a) The effects of particle size and inorganic mineral content on fines migration in fracturing proppant during coalbed methane production. J Petrol Sci Eng 182:106355. https://doi.org/10.1016/j. petrol.2019.106355

Wei Q, Li XQ, Hu BL, Zhang XQ, Zhang JZ, He YK, Zhang YC, Zhu WW (2019b) Reservoir characteristics and coalbed methane resource evaluation of deep-buried coals: A case study of the No. 13-1 coal seam from the Panji Deep Area in Huainan Coalfield, Southern North China. J Petrol Sci Eng 179:867-884. https://doi. org/10.1016/j.petrol.2019.04.100

Wu Y, Liu JS, Elsworth D, Chen ZW, Connell L, Pan ZJ (2010) Dual poroelastic response of a coal seam to $\mathrm{CO}_{2}$ injection. Int J Greenh Gas Con 4(4):668-678. https://doi.org/10.1016/j.ijggc .2010 .02 .004

Xia TQ, Zhou FB, Gao F, Kang JH, Liu JD, Wang JG (2015) Simulation of coal self-heating processes in underground methane-rich coal seams. Int J Coal Geol 141:1-12. https://doi.org/10.1016/j. coal.2015.02.007
Xiong P, Hu WS, Hu HX, Liu HL (2020) Mechanism of shear failure near fracture face during drainage process of CBM well. J Petrol Explor Prod Technol 10:3309-3317. https://doi.org/10.1007/ s13202-018-0467-y

Xu JZ, Zhai C, Ranjith PG, Sun Y, Qin L (2019) Petrological and ultrasonic velocity changes of coals caused by thermal cycling of liquid carbon dioxide in coalbed methane recovery. Fuel 249:15-26. https://doi.org/10.1016/j.fuel.2019.03.089

Yan J, Lu YY, Zhong DL, Zou ZL, Li JB (2019) Enhanced methane recovery from low-concentration coalbed methane by gas hydrate formation in graphite nanofluids. Energy 180:728-736. https://doi. org/10.1016/j.energy.2019.05.117

Yang RY, Huang ZW, Li GS, Sepehrnoori K, Lin Q, Cai CZ (2017) Integrity Testing of a Polyvinyl Chloride slotted liner for horizontal Coalbed-Methane wells. SPE Drill Complet 32(02):86-96. https://doi.org/10.2118/185958-PA

Yang RY, Huang ZW, Yu W, Lashgari H, Sepehrnoori K (2018) A semianalytical method for modeling two-phase flow in coalbedmethane reservoirs with complex fracture networks. SPE J. https ://doi.org/10.15530/urtec-2016-2460741

Yu Y, Wang Y (2020) Characteristics of low-rank coal reservoir and exploration potential in Junggar Basin: new frontier of lowrank CBM exploration in China. J Petrol Explor Prod Technol 10:2207-2223. https://doi.org/10.1007/s13202-020-00923-3

Zhang CL, Xu J, Peng SJ, Li QX, Yan FZ, Chen YX (2018) Dynamic behavior of gas pressure and optimization of borehole length in stress relaxation zone during coalbed methane production. Fuel 233:816-824. https://doi.org/10.1016/j.fuel.2018.06.132

Publisher's Note Springer Nature remains neutral with regard to jurisdictional claims in published maps and institutional affiliations. 